\title{
Production of glucose from the acid hydrolysis of anhydrosugars
}

\author{
Paula H Blanco, Jai Lad, Anthony V. Bridgwater, and Martin S. Holm
}

ACS Sustainable Chem. Eng., Just Accepted Manuscript • DOI: 10.1021/

acssuschemeng.8b02202 • Publication Date (Web): 17 Aug 2018

Downloaded from http://pubs.acs.org on August 22, 2018

\section{Just Accepted}

"Just Accepted" manuscripts have been peer-reviewed and accepted for publication. They are posted online prior to technical editing, formatting for publication and author proofing. The American Chemical Society provides "Just Accepted" as a service to the research community to expedite the dissemination of scientific material as soon as possible after acceptance. "Just Accepted" manuscripts appear in full in PDF format accompanied by an HTML abstract. "Just Accepted" manuscripts have been fully peer reviewed, but should not be considered the official version of record. They are citable by the Digital Object Identifier (DOI®). "Just Accepted" is an optional service offered to authors. Therefore, the "Just Accepted" Web site may not include all articles that will be published in the journal. After a manuscript is technically edited and formatted, it will be removed from the "Just Accepted" Web site and published as an ASAP article. Note that technical editing may introduce minor changes to the manuscript text and/or graphics which could affect content, and all legal disclaimers and ethical guidelines that apply to the journal pertain. ACS cannot be held responsible for errors or consequences arising from the use of information contained in these "Just Accepted" manuscripts. 


\title{
Production of glucose from the acid hydrolysis of anhydrosugars
}

Blanco, P. H ${ }^{a *}$, Lad, J. B ${ }^{a}$, Bridgwater A. V. ${ }^{a}$, Holm, M. S. ${ }^{b}$

*Email: p.blanco-sanchez@aston.ac.uk

${ }^{a}$ European Bioenergy Research Institute (EBRI), Aston University. The Aston Triangle B4 7ET, Birmingham, United Kingdom; ${ }^{b}$ Nova Pangaea Technologies. Lealholme building, Wilton International, Middlesbrough, TS90 8WS, Teesside, United Kingdom.

\begin{abstract}
Two anhydrosugar model compounds (cellobiose and levoglucosan), and a mixture of anhydrosugars from the fast-pyrolysis of birch wood were subjected to acid hydrolysis using sulfuric acid as catalyst. The anhydrosugars mixture or bio-oil aqueous fraction was found to contain mainly levoglucosan with a concentration of $30 \mathrm{~g} \mathrm{~L}^{-1}$. Hydrolysis temperature, reaction time, and catalyst to substrate molar ratios (c/s), were varied to identify their influence for glucose production. At $120^{\circ} \mathrm{C}, 60$ minutes, and $0.9 \mathrm{c} / \mathrm{s}$ ratio; glucose yields of $98.55 \%$ and $96.56 \%$, and substrate conversions of $100 \%$ and $\sim 92 \%$, were achieved when hydrolysing cellobiose and levoglucosan respectively. An increase in the temperature to 135 ${ }^{\circ} \mathrm{C}$, resulted in a decrease in both glucose yield and selectivity; whereas substrate conversions around $90 \%$ were maintained for both anhydrosugars. During the hydrolysis of the bio-oil fraction, a range of conditions to achieve glucose yields above $90 \%$, was depicted. It was found that $\mathrm{c} / \mathrm{s}$ ratios between 0.17 and 0.90 , and temperatures between 118 ${ }^{\circ} \mathrm{C}$ and $126{ }^{\circ} \mathrm{C}$ were suitable to achieve glucose yields around $100 \%\left(30 \mathrm{~g} \mathrm{~L}^{-1}\right)$. Furthermore glucose concentrations $\sim 117 \%$ (35 $\mathrm{g} \mathrm{L}^{-1}$ ) and levoglucosan conversions above $90 \%$, were attained at $135^{\circ} \mathrm{C}, 20$ minutes and 0.2 estimated c/s ratio.
\end{abstract}

Keywords: hydrolysis, glucose, anhydrosugars, levoglucosan, cellobiose 


\section{Introduction}

Renewable liquid fuels, high-value chemicals, and derived products can be obtained from the thermal processing of lignocellulosic biomass, for example via fast pyrolysis. During fastpyrolysis, the solid lignocellulosic biomass is thermally converted in the absence of oxygen, into three main fractions namely char, gases, and pyrolysis oil, the latter commonly called bio-oil [1-5].

Bio-oil can contain more than 400 compounds covering a wide range of molecular weights and functionalities [6-8]. The overall bio-oil composition highly depends upon the type of lignocellulosic material used as feedstock, and the pyrolysis processing conditions e.g. temperature and residence time [6, 9]. The major reported components of bio-oils include water, carboxylic acids, ketones, phenols, furans, and anhydrosugars [10, 11].

During fast pyrolysis, the cellulose present in lignocellulosic biomass, degrades into diverse products including anhydrosugars such as 1,6-anhydro- $\beta$-D-glucopyranose, referred to as levoglucosan (LG). Levoglucosan is a relevant anhydrosugar, which can be hydrolysed to monomeric glucose, which is a valuable chemical platform that can be fermented to produce bio-fuels such as bio-ethanol and bio-butanol [9, 12-14]. Alternatively, levoglucosan in the bio-oil can be separated for crystallization which opens valorisation routes of the anhydrosugar itself as compared to glucose [15].

The bio-oil fraction normally contains an aqueous and a non-aqueous fraction that can be separated for example by extraction. The aqueous extract of bio-oil is composed by low molecular weight aldehydes such as glycoaldehyde as well as phenolic compounds [16]. Anhydrosugars such as levoglucosan are also normally present in the bio-oil aqueous fraction, and some studies have been directed in optimising levoglucosan extraction [9, 12]. For example Li et al. 2013 [12], used water during the extraction of levoglucosan from bio-oil in order to maximise the amount of levoglucosan obtained. The optimal parameters reported included a water-to-bio-oil ratio of $1.3: 1,25^{\circ} \mathrm{C}$, and 20 min extraction time to yield $12.7 \mathrm{wt} . \%$ of levoglucosan. Bennet et al., 2009 [9], studied the extraction of levoglucosan from bio-oil, and its further hydrolysis to produce glucose. The optimal conditions reported for the extraction stage were $41 \mathrm{wt} \%$ of water at $34{ }^{\circ} \mathrm{C}$, which resulted in an aqueous fraction containing about $88 \mathrm{~g} \mathrm{~L}^{-1}$ of levoglucosan. A glucose yield as high as $216 \%$ (based on levoglucosan in the substrate) was reported during the hydrolysis of levoglucosan at $125^{\circ} \mathrm{C}$, 44 minutes reaction time and using $0.5 \mathrm{M}$ sulphuric acid [9]. The extraction of levoglucosan is seem as a necessary step when the levoglucosan is further processed via hydrolysis.

To date, several studies have indicated that levoglucosan yields in bio-oil can be greatly increased if a mild or dilute acid biomass pre-treatment precedes the fast pyrolysis [12, 17- 
21]. For example Scott D. S., et al., [17], examined the production of anhydrosugars from cellulose-containing biomass via a series of processes. The first step was a biomass pretreatment with diluted acid in order to remove alkaline materials, which was followed by the separation of cellulose and hemicellulose fractions. Then the solid hemicellulose-free fraction was subjected to fast pyrolysis at temperatures between $400-650{ }^{\circ} \mathrm{C}$ and residence time $<10$ seconds, and finally the anhydrosugars produced were isolated [17].

Lian et al., [7], pyrolysed acid washed poplar at with an organic phase (containing phenols) and an aqueous phase containing anhydrosugars. The anhydrosugars were separated from phenols by solvent extraction and then subjected to acid hydrolysis using sulphuric acid as catalyst. The HPLC analysis of the phenol-rich fraction, revealed the presence of levoglucosan, sorbitol, cellobiosan, arabinose, galactose, glucose, mannose/xylose, fructose, cellobiose, and some other unknown compounds. After acid hydrolysis at $120{ }^{\circ} \mathrm{C}$, 42 minutes and using $\mathrm{H}_{2} \mathrm{SO}_{4} 0.5 \mathrm{M}$ as catalyst, a glucose yield of $220 \%$ was achieved. This high glucose yield was attributed to the contribution of unidentified anhydrosugars into the final glucose formation [7].

Acid hydrolysis is one of the most common processes to obtain low-cost fermentable sugars from anhydrosugars. However, it is a complex process as several parameters can be varied including temperature, residence time, acid catalyst type, acid concentration, and catalyst to anhydrosugars ratio. Meaning that many experiments need to be conducted to clearly identify clear trends for glucose yields. So far in the literature there have been a handful of reported studies on acid hydrolysis of anhydrosugar model compounds such as levoglucosan and cellobiose [22-24]. However little has been reported about the acid hydrolysis of bio-oil fractions at different conditions [9, 22].

The feasibility of a bio-refinery concept in which an anhydrosugar-rich liquid from the fast steam pyrolysis of birch-wood is hydrolysed into glucose, with the intention for it to be fermented into bio-ethanol or bio-butanol as a fuel is experimentally addressed in this work. The acid loading and reaction time will affect the economics of the overall process pronouncedly, so in-depth information about this important reaction step is required.

Ultimately this work experimentally investigated the potential of obtaining glucose from the acid hydrolysis of anhydrosugars. Initially levoglucosan and cellobiose were used as anhydrosugar model compounds. The influence of selected hydrolysis conditions over both the conversion of anhydrosugar model compounds and glucose yields was analysed. In a second stage an anhydrosugars mixture from bio-oil was hydrolysed; glucose concentrations and substrate conversions were studied also at different hydrolysis conditions. Overall the 
hydrolysis parameters varied included reaction time, temperature and catalyst/substrate molar ratios.

\section{Materials and methods}

\section{Materials}

\section{Anhydrosugars}

For the anhydrosugar model compounds, levoglucosan (CAS 498-07-7) and D-cellobiose (CAS 528-50-7) were purchased from Carbosynth Limited, Berkshire, United Kingdom. Solutions of levoglucosan and cellobiose were prepared at concentrations of $62.3 \mathrm{~g} \mathrm{~L}^{-1}$, and $100 \mathrm{~g} \mathrm{~L}^{-1}$ respectively. The concentration of the levoglucosan solution was adjusted to this value, as it was expected that the real anhydrosugars mixture from bio-oil will contain about $60 \mathrm{~g} \mathrm{~L}^{-1}$ of levoglucosan.

\section{HPLC compounds}

For the HPLC calibration, solutions of levoglucosan, cellobiose, together with solutions of cellobiosan (CAS 35405-71-1, Carbosynth Limited UK), and glucose (CAS 50-99-7, SigmaAldrich) were used. For the HPLC mobile phase, the following substances were used: water, acetonitrile (ACN), both HPLC grade from VWR chemicals, and a solution of $100 \mathrm{mM}$ ammonium acetate (Sigma-Aldrich). The $\mathrm{pH}$ of the ammonium acetate solution was adjusted to $\mathrm{pH}=5.4$ using a concentrated hydrochloric acid $(\mathrm{HCl}$, Sigma-Aldrich). The percentages to prepare the mobile phase were $75 \mathrm{vol} . \% \mathrm{ACN}, 15 \mathrm{vol} . \%$ water, and $10 \mathrm{vol} . \% 100 \mathrm{mM}$ ammonium acetate solution.

\section{Liquid acid catalyst}

For the homogeneous catalyst, concentrated sulfuric acid $\left(\mathrm{H}_{2} \mathrm{SO}_{4}>95 \%\right.$, from Fisher Chemicals), it was used to prepare a $0.5 \mathrm{M}$ sulfuric acid solution. This solution was used for all the hydrolysis tests reported in this work. The volumes of acid catalyst and substrates were therefore varied in order to achieve different catalyst/substrate ratios.

\section{Aqueous fraction of bio-oil}

The aqueous fraction was extracted from a bio-oil prepared by Nova Pangaea Technologies, in the United Kingdom. Birch-wood chips from UK were used as feedstock for the fast pyrolysis. Initially hemicelluloses and alkali materials were removed from the biomass by a dilute sulphuric acid based hemicellulose hydrolysis process $\left(\mathrm{H}_{2} \mathrm{SO}_{4}\right.$ : biomass $\left.\sim 0.02: 1.0\right)$, at $170{ }^{\circ} \mathrm{C}$, and $15 \mathrm{~min}$. The use of dilute acid $\left(\mathrm{H}_{2} \mathrm{SO}_{4}<2 \mathrm{wt} . \%\right)$ as pre-treatment to alter or break the structure of lignocellulosic biomass is a widely used technique. It is mainly used to remove hemicelluloses in the form of sugars and oligomers with limited effects on cellulose 
and lignin compounds. This pre-treatment involves low acid consumption and increases the material's porosity [25-29]. Commercial processes using sulfuric acid as pre-treatment for biomass include BlueFire Renewables (USA), and Abengoa Bioenergy (Spain) [25, 30].

The hydrolysed hemicellulose fraction was segregated, and the pre-treated stream was subjected to a fast steam pyrolysis process. A continuous pyrolysis reaction with a capacity of $15-25 \mathrm{~kg} / \mathrm{h}$ was used to process the pre-treated biomass. For the pyrolysis about $4.5 \mathrm{~kg}$ of superheated steam were added per $\mathrm{kg}$ of dry biomass feed, the pyrolysis temperature was around $380-410^{\circ} \mathrm{C}$, the pressure $\sim 1 \mathrm{~atm}$ and a short biomass residence time in the order of seconds were used as process conditions. Under these conditions about $75 \mathrm{wt} . \%$ of liquid fraction (wet basis), 20wt.\% solid fraction (char), and $5 \mathrm{wt} . \%$ of gases (dry basis) were produced. The aqueous fraction from the condensed pyrolysis liquid was segregated from non-aqueous fraction, as it was known to contain anhydrosugars. The aqueous fraction containing anhydrosugars was characterised using HPLC and GC-MS, in order to identify its major components. The aqueous bio-oil fraction was stored at $4{ }^{\circ} \mathrm{C}$ with no light exposure until used for the hydrolysis tests.

\section{Methods}

\section{Experimental: Acid hydrolysis}

The anhydrosugar model compounds (cellobiose and levoglucosan) and the aqueous fraction from the bio-oil were subjected to acid hydrolysis. A schematic of the $15 \mathrm{~mL}$ autoclave reaction system used for the hydrolysis experiments is shown in Figure 1. The reagents were loaded at atmospheric pressure, and due to the closed nature of the system the pressure slightly increased to autogenous pressure of water about 2 bar to 6 bar, when using temperatures of $135^{\circ} \mathrm{C}$ and $150{ }^{\circ} \mathrm{C}$ respectively. The influence of an inert vs an air atmosphere on the glucose yield, was not studied as it was not within the scope of this research. During the hydrolysis tests the parameters selected to be varied included temperature, reaction time, and catalyst to substrate molar ratio.

A typical hydrolysis experiment was carried out as a batch experiment (Figure 1); certain volume of substrate solution with a fixed concentration (cellobiose, levoglucosan, or pyrolysis-oil), was loaded in a glass liner together with a magnetic stirrer and the calculated volume of catalyst $\left(0.5 \mathrm{M} \mathrm{H}_{2} \mathrm{SO}_{4}\right)$. The total volume for all the hydrolysis experiments was kept constant at $10 \mathrm{~mL}$ and only the volumes of both substrate solution and sulphuric acid were varied in order to achieve different catalyst/substrate molar ratios. For all the experiments stirring was set at $600 \mathrm{RPM}$ and a heating rate of about $2.5^{\circ} \mathrm{C} \mathrm{min}{ }^{-1}$ was used until reaching the set temperature $\left( \pm 3^{\circ} \mathrm{C}\right)$. The reaction time began to be measured once the temperature reached the set value. 
The independent variables for acid hydrolysis were $X_{1}, X_{2}$, and $X_{3}$, representing the temperature in ${ }^{\circ} \mathrm{C}$, reaction time in minutes, and catalyst/substrate molar ratio respectively. Each variable was coded at three levels $(-1,0,1)$; these coded values were obtained according to Eq. (1):

$$
C V=\frac{(A V-M)}{H R}
$$

where $C V$ is the coded value, $A V$ is the actual value, $M$ is the mean and $H R$ is the half of range. Values were considered for each test, and a matrix of coded factor levels was obtained as shown in Table 1. The initial fixed conditions were temperatures of $80{ }^{\circ} \mathrm{C}, 100$ ${ }^{\circ} \mathrm{C}$, and $120^{\circ} \mathrm{C}$, reaction times of 20,40 , and 60 minutes, and catalyst to substrate molar ratios of $0.2,0.6$, and 0.9 . All these values were selected based on hydrolysis conditions reported in the literature. Additional experiments were carried out at $135{ }^{\circ} \mathrm{C}$ and $150{ }^{\circ} \mathrm{C}$, in order to study the decomposition routes of the anhydrosugars at higher temperatures.

After each hydrolysis test, the resulting samples were analysed using HPLC and the concentrations of the different compounds were calculated using their corresponding calibration curves. The conversion of substrate (cellobiose or levoglucosan), represented how much out of the initial $100 \%$ of substrate was converted during the reaction, and it can be expressed by Eq. (2):

$$
C_{s}=100-\left[\frac{\left(Y_{i s}-Y_{f s}\right)}{Y_{i}} \times 100\right]
$$

where $C_{S}$ is the conversion of substrate in percent (\%); $Y_{i s}$ are the initial moles of the substrate at $t=0$, and $Y_{f s}$ are the final moles of substrate after acid hydrolysis.

The glucose yields were calculated considering the actual and theoretical glucose amounts. The actual glucose was calculated by Eq. (3):

$$
A_{G}=Y_{f G} \times M_{G}
$$

where $A_{G}$ indicates the actual amount of glucose in grams $(\mathrm{g}), Y_{f G}$ represent the final moles of glucose after hydrolysis, and $M_{G}$ is the molecular weight of glucose $(180.16 \mathrm{~g} / \mathrm{mol})$.

The theoretical amount of glucose was then calculated using Eq. (4):

$$
T_{G}=Y_{i s} \times M_{G}
$$

where $T_{G}$ is the theoretical maximum amount of glucose in grams $(\mathrm{g})$, and $Y_{i s}$ are the initial moles of substrate. The $1: 1$ and 1:2 stoichiometry (moles) were used to calculate the theoretical amount of glucose from the hydrolysis of levoglucosan and cellobiose respectively. 
The overall glucose yield was therefore obtained combining the theoretical and actual glucose amounts, and using the following expression (Eq. (5)):

$$
G_{Y}=\left(\frac{A_{G}}{T_{G}}\right) \times 100
$$

where $G_{Y}$, is the glucose yield in percent (\%); $A_{G}$ is the actual glucose $(\mathrm{g})$, and $T_{G}$ is the theoretical amount of glucose in grams $(\mathrm{g})$.

Finally, the selectivity was calculated considering the conversion of the substrate to glucose, using the following Eq. (6), and reported by Deng et al [31]:

$$
S=\left(\frac{Y_{f G}}{Y_{i s}-Y_{f s}}\right) \times 100
$$

where $Y_{f G}$ are the moles of glucose in the final product, $Y_{i s}$ and $Y_{f s}$ are the initial and final moles of substrate. When calculating the selectivity of glucose from the substrate cellobiose, the denominator was multiplied by 2 , considering the reaction stoichiometry.

\section{Characterisation of bio-oil aqueous fraction}

In the present research the bio-oil from fast pyrolysis was extracted or separated into water soluble and water-insoluble fractions. Similar procedures have been reported in the literature by Yu et al, 2016 [32]; Lian et al, 2010 [7], and Bennett et al, 2009 [9].

The water soluble or aqueous fraction of bio-oil, was characterised using diverse techniques in order to identify its major compounds.

\section{Moisture content}

Initially the water content of the bio-oil was quantified using a Mettler Toledo V20 Volumetric Karl-Fisher Titrator as per American Society for Testing and Materials (ASTM) E203-96. It was determined that the pyrolysis oil had a water content higher than $90.0 \%$. This water content, together with the water contained in the liquid acid catalyst $\left(0.5 \mathrm{M} \mathrm{H}_{2} \mathrm{SO}_{4}\right)$, contributed to the hydrolysis process.

\section{GC-MS}

A Varian 450-GC gas chromatograph, coupled to a Varian 220-MS, IT mass spectrometer (GC-MS), was used for the analysis of the chemical compounds contained in the aqueous fraction of the pyrolysis oil and in some hydrolysates. The system was equipped with a capillary column Elite-1701, L $30 \mathrm{~m} \times$ I. D. $0.25 \mathrm{~mm}, \mathrm{~d}_{\mathrm{f}} 0.25 \mu \mathrm{m}$. The identification of the compounds was based on the existing library for different types of bio-oil. 


\section{HPLC}

All the samples from acid hydrolysis tests were analysed by high-performance liquid chromatography (HPLC), using a 1200 Infinity Series from Agilent Technologies equipped with an auto sampler, gradient pump, and UV/ RI detection systems. The separation of sugars was performed using a $2.6 \mu \mathrm{m} 150$ Amide-HILIC HPLC column $(250 \times 2.1 \mathrm{~mm}$ with guard $10 \times 3.0 \mathrm{~mm}$ ). The column was set at $30{ }^{\circ} \mathrm{C}$ with a flowrate $0.1 \mathrm{~mL} \mathrm{~min}^{-1}$, and an injection volume of $5 \mu \mathrm{L}$. The mobile phase used was 75/10/15 (ACN/100 mM ammonium acetate $\mathrm{pH} 5.4 / \mathrm{H}_{2} \mathrm{O}$ ); $1 \mathrm{~L}$ of the solution was premixed in order to avoid variations in the RI signal when using the mixing pump.

The HPLC column was calibrated using prepared stock solutions of levoglucosan, cellobiose, cellobiosan, and glucose at 5 different concentrations. Linear calibration curves (average $\mathrm{R}^{2}=0.997$ ) were obtained for each compound and the elution times for the different compounds were identified. Each sample was analysed in duplicate and the average was used to report the concentration of each compound. During HPLC analysis, the typical relative standard error was \pm 0.00026 for multiple injections from the same sample.

\section{Results and discussion}

\section{Acid hydrolysis of cellobiose}

Cellobiose is not commonly identified as a component of pyrolysis oil, however it was selected as it can be formed as intermediate during the acid hydrolysis of cellobiosan; the latter is a common compound present in the bio-oil composition together with levoglucosan $[24,32,33]$. During the hydrolysis of cellobiosan, two molecules of glucose can be formed via two different routes as shown in Figure 2 [24, 34]. The upper path occurs via the hydrolysis of $\beta-(1 \rightarrow 4)$ glycosidic bonds to form one molecule of glucose and one molecule of levoglucosan, then levoglucosan might further hydrolyse into glucose [35]. The second glucose formation route from cellobiosan is via the hydrolysis of 1,6-anhydro bond, resulting in the formation of the disaccharide cellobiose. Cellobiose can further hydrolyse yielding two molecules of glucose via rupture of the O-glycosidic bond (Figure 2).

For the hydrolysis of cellobiose different temperatures $\left(80,100\right.$, and $\left.120^{\circ} \mathrm{C}\right)$, reaction times $(20,40$, and $60 \mathrm{~min})$, and catalyst to substrate molar ratios $(0.2,0.6$, and 0.9$)$ were varied in order to identify their influence in both the glucose yield and substrate conversion (Table 1). The volumes of the cellobiose stock solution $\left(100 \mathrm{~g} \mathrm{~L}^{-1}\right)$, and catalyst $\left(\mathrm{H}_{2} \mathrm{SO}_{4}, 0.5 \mathrm{M}\right)$ were adjusted to achieve different catalyst/substrate molar ratios.

The effects of varying the hydrolysis parameters were studied via monitoring both cellobiose conversion and glucose yields, as shown in Figure 3 . Figure $3 a$, b, and c, depicts the 
aforementioned trends at 20, 40 and 60 min reaction times respectively. From Figure 3 it can be seen that at a hydrolysis temperature of $80{ }^{\circ} \mathrm{C}$, low substrate conversions and low glucose yields were achieved. For example at $80{ }^{\circ} \mathrm{C}$ (Figure 3 ) just between 20 and $30 \%$ of the initial cellobiose was converted, resulting in relatively low glucose yields between 2 and $15 \%$ at different reaction times and different catalysts to cellobiose ratios. At a hydrolysis temperature of $80{ }^{\circ} \mathrm{C}$, by increasing the reaction time from 40 minutes (Figure $3 \mathrm{~b}$ ) up to 60 minutes (Figure 3c), slightly increased the glucose yields from $7 \%$ up to $17 \%$, for a catalyst/substrate ratio of 0.6 whereas the glucose yield was maintained around $14 \%$ for 0.9 catalyst/substrate. In addition, the selectivity towards glucose increased from 0.4 up to 0.9 when increasing the catalyst/substrate ratio from 0.6 to 0.9 . Nevertheless, both the low conversion of cellobiose and relatively low glucose yields $(\sim 15 \%)$, were attributed to the mild hydrolysis temperature used.

At $120{ }^{\circ} \mathrm{C}$ and a catalyst to substrate ratio of 0.2 , the glucose yield increased from $60 \%$ to $77 \%$ as the hydrolysis time was increased from $20 \mathrm{~min}$ (Figure 3a) up to $60 \mathrm{~min}$ (Figure 3c); whereas at a ratio of 0.6 , the glucose yield remained somewhat constant around $87 \%$ regardless the reaction time. Full conversion of cellobiose at a ratio of 0.6 was seen after approximately 40 minutes at $120^{\circ} \mathrm{C}$. A very similar yield observed after 40 and 60 minutes indicates that only marginal glucose degradation occurs at this reaction condition. At $120{ }^{\circ} \mathrm{C}$ the further increase of the catalyst to substrate ratio from 0.6 up to 0.9 , resulted in a $100 \%$ conversion of cellobiose after $40 \mathrm{~min}$ (Figure 3b) and $60 \mathrm{~min}$ (Figure 3c) of hydrolysis. This is in accordance with reported results where the increase in the $\mathrm{H}_{2} \mathrm{SO}_{4}$ concentration increased the substrate conversion and thus the glucose yields [24]. For cellobiose hydrolysis, the highest glucose yield of $98 \%$ was achieved after $60 \mathrm{~min}$ (Figure 3c), $\mathrm{H}_{2} \mathrm{SO}_{4} /$ cellobiose ratio of 0.9 , and a reaction temperature of $120^{\circ} \mathrm{C}$, with a $100 \%$ cellobiose conversion.

In order to study the effect of further increasing the temperature during the hydrolysis of cellobiose, selected experiments were carried out at $135{ }^{\circ} \mathrm{C}, 40$ and 60 min reaction time, and 0.6 and 0.9 catalyst/substrate ratio. It was observed that all the experiments carried out at $135{ }^{\circ} \mathrm{C}$ resulted in a $100 \%$ conversion of cellobiose, but not necessarily $100 \%$ yield of glucose. For example at a catalyst/substrate of 0.6 and $135^{\circ} \mathrm{C}$, the glucose yield decreased from $92 \%$ down to $89.5 \%$, as the reaction time increased from $40 \mathrm{~min}$ up to $60 \mathrm{~min}$; showing that glucose degradation starts becoming significant at this temperature. Furthermore, the presence of levoglucosan was observed and its concentration was noted to increase from $2.4 \mathrm{~g} \mathrm{~L}^{-1}$ up to $3.4 \mathrm{~g} \mathrm{~L}^{-1}$ at the aforementioned hydrolysis conditions. It is postulated that the increase in the temperature from $120^{\circ} \mathrm{C}$ up to $135^{\circ} \mathrm{C}$, promoted the dehydration of glucose into levoglucosan as shown in Figure 5 [36, 37]. The dehydration of glucose into levoglucosan can occur via two pathways. The first one is the formation of a key 
intermediate that becomes stable due to the solvation energy due to the high temperature and high density of hot water. In the second route two water molecules close to glucose transfer hydrogen atoms into the hydroxyl groups of glucose, eliminating a water molecule from glucose. Then a bi-radical is formed, which can finally leads to the formation of levoglucosan [38].

The glucose selectivity after 60 minutes of reaction time is shown in Figure 4. From Figure 4 it is observed a positive influence of the temperature on the glucose selectivity (dashed lines). For example, for a catalyst/substrate ratio of 0.2 , the glucose selectivity gradually increases from $14 \%$ to $36 \%$, and up to $87 \%$, as the temperature increases from $80{ }^{\circ} \mathrm{C}$ to 100 ${ }^{\circ} \mathrm{C}$ and up to $120{ }^{\circ} \mathrm{C}$ respectively (Figure 4). At $120{ }^{\circ} \mathrm{C}$, the glucose selectivity increased from $87.6 \%$ to $98.5 \%$ when the catalyst to substrate ratio was increased from 0.6 up to 0.9 (Figure 4). Interestingly, the selectivity was reduced down to $86 \%$ when the temperature was increased up to $135{ }^{\circ} \mathrm{C}$ for a catalyst/substrate of 0.9 . This behaviour is therefore linked to the potential glucose dehydration reactions taking place at hydrolysis temperatures higher than $120^{\circ} \mathrm{C}$ (Figure 5).

The results from the experiments carried out at different temperatures were used to create a matrix and obtain a 3D surface area and contour plot for glucose yields from the hydrolysis of cellobiose (Figure 6). From Figure 6, it can be seen that glucose yields above $90 \%$ can be attained during the hydrolysis of cellobiose, at temperatures between $120-135^{\circ} \mathrm{C}$, and using catalyst/substrate ratios between 0.6 and 0.9 .

In order to study the influence of increasing the temperature beyond $135^{\circ} \mathrm{C}$, cellobiose hydrolysis tests were carried out at $150{ }^{\circ} \mathrm{C}, 10 \mathrm{~min}$, and at catalyst/substrate ratios of 0.6 and 0.9. Under these conditions it was observed that after $10 \mathrm{~min}$, the glucose yield was reduced from $83 \%$ down to $79 \%$ as the $\mathrm{H}_{2} \mathrm{SO}_{4}$ /cellobiose ratio increased from 0.6 up to 0.9 . Contrastingly glucose yields higher than $87 \%$ were attained when hydrolysing cellobiose at $120^{\circ} \mathrm{C}$ and $135^{\circ} \mathrm{C}, 40$ minutes of reaction time, at both 0.6 and 0.9 catalyst/substrate ratios.

For the hydrolysis experiments carried out at $150{ }^{\circ} \mathrm{C}$, there was a visual presence of solids in the collected sample, which has been related with the further degradation of glucose at high temperatures. For example the isomerization of glucose into fructose, followed by the dehydration of fructose into 5-hydroxymethyl furfural (5-HMF), as shown in Figure 5 [39]. The resulting 5-HMF (Figure 5) is an unstable molecule which tends to condense into a black insoluble carbonaceous heterogeneous materials, often referred to as "humins" [4047]. Alternatively the subsequent addition of water (hydration reaction) to the $C_{2}-C_{3}$ bond of the furan ring in the 5-HMF structure, might yield to both levulinic acid and formic acid in a $1: 1 \mathrm{~mol}$ ratio [44]. van Zandvoort et al., 2013 [44], reported humins yields up to $36 \%$ when 
hydrolysing glucose at $113{ }^{\circ} \mathrm{C}$ and $247^{\circ} \mathrm{C}$, and after $6 \mathrm{~h}$ of reaction, and found a strong relationship between the humins yield and temperature rather than acid concentration and humins yield. Generally, the presence of humins in hydrolysis product indicates that $150{ }^{\circ} \mathrm{C}$ temperature is too harsh for high yield glucose production $[44,45]$.

\section{Acid hydrolysis of levoglucosan}

As shown in Table 1 the conditions for acid hydrolysis of levoglucosan were the same as those described for the hydrolysis of cellobiose. However as demonstrated by Figure 2, the theoretical quantity of glucose was calculated using a 1:1 molar stoichiometry (levoglucosan into glucose).

The conversion of levoglucosan and glucose yields at $80{ }^{\circ} \mathrm{C}, 100{ }^{\circ} \mathrm{C}, 120{ }^{\circ} \mathrm{C}$; $\mathrm{H}_{2} \mathrm{SO}_{4} /$ levoglucosan molar ratios of $0.2,0.6,0.9$; and reaction times of $20 \mathrm{~min}, 40 \mathrm{~min}$ and $60 \mathrm{~min}$, are shown in Figure 7. Similar to the trends observed for cellobiose hydrolysis (Figure 3), at $80^{\circ} \mathrm{C}$ both levoglucosan conversions and glucose yields $<11 \%$ were obtained at $20 \mathrm{~min}$ (Figure 7a) and $40 \mathrm{~min}$ (Figure 7b), whereas a slight increase in the glucose yield up to $14 \%$ is observed after $60 \mathrm{~min}$ (Figure 7c). At $80{ }^{\circ} \mathrm{C}, 0.6$ ratio, and 60 minutes, levoglucosan conversion was just 10\% (Figure 7), whereas the conversion of cellobiose under similar hydrolysis conditions was $\sim 33 \%$ (Figure 3 ). Which shows that at this relatively low temperature of $80{ }^{\circ} \mathrm{C}$, the conversion of cellobiose occurs at a faster rate when compared with the hydrolysis of levoglucosan.

When the levoglucosan hydrolysis temperature was increased to $100{ }^{\circ} \mathrm{C}$, glucose yields as high as $85 \%$, and $\sim 90 \%$ levoglucosan conversion were attained, after 60 minutes of reaction time and 0.6 catalyst/substrate molar ratio (Figure 7c). At $100{ }^{\circ} \mathrm{C}$, and 20 minutes of reaction time (Figure $7 \mathrm{a}$ ), an increase in the catalyst/substrate ratio from 0.2 to 0.6 increased the glucose yield from $21 \%$ up to $32 \%$. Experiments at a catalyst/substrate ratio of 0.2 revealed that an increase in the temperature from $80{ }^{\circ} \mathrm{C}$ up to $100{ }^{\circ} \mathrm{C}$, had a similar effect than increasing the catalyst/substrate ratio from 0.2 up to 0.9 (Figure 7). This means that either the increase in the sulfuric acid at a given temperature, or the increase in the temperature at a given sulfuric acid concentration, can have similar effects towards both levoglucosan conversion rate and glucose yield [24].

However it was observed that the further increase in the temperature from $100^{\circ} \mathrm{C}$ up to 120 ${ }^{\circ} \mathrm{C}$ (Figure 7), had a major influence on both levoglucosan conversion and glucose yields. For example at $120{ }^{\circ} \mathrm{C}$, levoglucosan conversions around $99 \%$ and glucose yields $90-100 \%$ were achieved for all the hydrolysis conditions tested. The levoglucosan conversion trends observed by increasing the temperature up to $120^{\circ} \mathrm{C}$, are in agreement with previous results reported by Bennett et al, 2009, and Helle et al, 2007 [9, 24]. 
Levoglucosan conversions and glucose concentrations at different reaction times $(20,40,60$ minutes) and temperatures $\left(80^{\circ} \mathrm{C}, 100{ }^{\circ} \mathrm{C}, 110^{\circ} \mathrm{C}\right.$, and $\left.120^{\circ} \mathrm{C}\right)$, are shown in Figure 8 . From Figure 8 values for levoglucosan conversion and glucose concentration at $110{ }^{\circ} \mathrm{C}$ were calculated using the first-order kinetic equations reported by Helle et al, 2007 [24], for the hydrolysis of levoglucosan. Equations (6) and (7), allowed us to estimate the concentrations for levoglucosan and glucose at $110^{\circ} \mathrm{C}$, respectively

$$
\begin{gathered}
\frac{A}{A_{o}}=e^{-k_{1} t} \\
\frac{D}{A_{o}}=\left(1-e^{-k_{1} t}\right)
\end{gathered}
$$

Where $A$ and $D$, are the concentrations of levoglucosan and glucose, respectively, and $k_{1}$ is the first order rate constant for the hydrolysis of levoglucosan $\left(0.00135 \mathrm{~s}^{-1}\right) ; A_{0}$ is the initial concentration of levoglucosan.

Figure 8 aims to show the proximity between our experimental data and that calculated using a kinetic expression reported somewhere else [24]. From Figure 8, a major increase in the glucose concentration and levoglucosan conversion was observed for temperatures above $100{ }^{\circ} \mathrm{C}$, even at the low catalyst/substrate ratio of 0.2 . The calculated data at $110{ }^{\circ} \mathrm{C}$ was obtained using a kinetic constant $\left(k_{1}\right)$ for $\mathrm{H}_{2} \mathrm{SO}_{4}, 500 \mathrm{mM}$. For our experimental values at $120{ }^{\circ} \mathrm{C}$ we used the same acid concentration and a catalyst/substrate ratio of 0.2 . The calculated kinetic values were slightly above our experimental ones, which indicated that a good estimation can be obtained based on the kinetics, however experimental data is also necessary to verify these estimated trends.

Similar to the cellobiose hydrolysis analysis, the influence of further increasing the levoglucosan hydrolysis temperature was studied. Hydrolysis experiments were carried out at $135{ }^{\circ} \mathrm{C}$, reaction times of $10 \mathrm{~min}, 40 \mathrm{~min}$ and $60 \mathrm{~min}$, at catalyst/substrate molar ratios of 0.6 and 0.9 . The results were integrated with the previous ones in order to create a matrix and to obtain a 3D surface area and a contour plot as shown in Figure 9.

In general, glucose yields following cellobiose hydrolysis (Figure 3) were lower than those obtained from the levoglucosan hydrolysis (Figure 7). For example, at a hydrolysis temperature of $120{ }^{\circ} \mathrm{C}$, average glucose yields of $83 \%$ and $93 \%$ were obtained for the hydrolysis of cellobiose and levoglucosan respectively. Furthermore, at $120{ }^{\circ} \mathrm{C}$ values for glucose selectivity of $91 \%$ and $98 \%$ were calculated for the hydrolysis of cellobiose and levoglucosan respectively. This means that glucose selectivity is favoured for hydrolysing levoglucosan rather than cellobiose under similar conditions. This variation can be related to the slower rate of reaction during the hydrolysis of cellobiose, associated to the kinetics of 
this particular reaction [24]. This can also explain the different patterns showed in the contour plots for the hydrolysis of cellobiosan (Figure 6b) and levoglucosan (Figure 9b). Whereas for hydrolysis of cellobiosan, glucose yields higher than $80 \%$ are concentrated at temperatures around $120{ }^{\circ} \mathrm{C}$ and $135{ }^{\circ} \mathrm{C}$ and catalyst/substrate ratios of 0.45 and 0.9 (Figure 6); for levoglucosan this area is greater from temperatures between $110{ }^{\circ} \mathrm{C}$ up to $135{ }^{\circ} \mathrm{C}$, and catalyst/substrate ratios of 0.2 up to 0.9 (Figure 9).

For the hydrolysis levoglucosan at $150{ }^{\circ} \mathrm{C}, 10$ minutes at catalyst/substrate molar ratios of 0.6 and 0.9 , glucose yields around $67 \%$ were obtained, with conversions of substrate around $80 \%$. It is worth to mention that 5 -HMF was also identified in the hydrolysates (GC-MS), which might indicate the further degradation of this particular compound into humins. This was observed physically as also solids were observed in the collected hydrolysate samples. During the hydrolysis tests at $135^{\circ} \mathrm{C}$ and $150^{\circ} \mathrm{C}$, the pressure in the autoclave system went up to 2 bar and 6 bar respectively, which was due to the nature of the closed system and higher reaction temperatures, but it might have implications when thinking about scaling up the process at these conditions as the reaction system should be capable to cope with these conditions.

\section{Acid hydrolysis of aqueous bio-oil fraction}

The extracted aqueous fraction from the bio-oil was analysed by GC-MS and HPLC. The GC-MS chromatogram of this fraction is shown in Figure 10. From Figure 10, it is observed that the major compound identified by GC-MS it was levoglucosan, as the area of this compound represented about $75 \%$ among all the peaks identified. Other major compounds identified by GC-MS included furfural, guaiacol, 2-methoxy-4-methylphenol, 5-hydroxymethyl furfural (5-HMF), syringol, 1,2,4-trimethoxy benzene, syringaldehyde, and possibly the last peak corresponds to 1,6-anhydro- $\beta$-D-glucofuranose. This last compound is a furanose isomer of levoglucosan and it has been has been proven to be present in similar pyrolysis products $[48,49]$. The presence of this particular compound can also be attributed to the dehydration of glucose as shown in Figure 5. However, a conclusive assignment could not be achieved due to the unavailability of the pure 1,6-anhydro- $\beta$-D-glucofuranose.

From HPLC analysis of the aqueous fraction, it was determined that the initial concentrations of levoglucosan and cellobiosan were $31 \mathrm{~g} \mathrm{~L}^{-1}(3.1 \mathrm{w} / \mathrm{v} . \%)$ and $2.1 \mathrm{~g} \mathrm{~L}^{-1}$ (0.021 w/v.\%), respectively. Also other unknown compounds, possibly anhydrosugars and acids, might be present in the aqueous fraction as several unidentified peaks were observed by both GC-MS and HPLC analysis (Figure 10). Previous studies [12, 18, 50, 51], have identified monomeric and oligomeric (anhydro)-sugars such as cellobiosan and levoglucosan as bio-oil component in pyrolysis oil from the fast pyrolysis of different biomass, being levoglucosan the most 
abundant anhydrosugar. For example Dobele et al., 2003 [18], reported about 15 wt.\% from the analytical pyrolysis of birch wood sawdust; Li et al., 2013 [50], reported about 16 wt.\% of levoglucosan in the organic fraction of pyrolysis liquids from red oak; and Oudenhoven and collaborators, 2015 [51], reported $\sim 35$ wt.\% of levoglucosan in pyrolysis liquids condensed at $80{ }^{\circ} \mathrm{C}$ from acid leached biomasses. Also Lian et al., 2010 [7] reported that the aqueous phase of bio-oil from the pyrolysis of acid washed poplar contained $19 \mathrm{~g} \mathrm{~L}^{-1}$ of levoglucosan and $15 \mathrm{~g} \mathrm{~L}^{-1}$ of cellobiosan. Overall, the variability in the bio-oil composition and therefore the composition of the aqueous fraction, depends upon the reactor's configuration, feedstock, and pyrolysis process conditions.

During the hydrolysis of the bio-oil aqueous fraction, the catalyst to substrate ratios were estimated considering the initial concentration of levoglucosan of $31 \mathrm{~g} \mathrm{~L}^{-1}$ obtained by HPLC. Levoglucosan was used as reference compound to estimate the catalyst to substrate molar ratios, as it was the anhydrosugar present in the bio-oil in a higher concentration (Figure 10). When calculating glucose yields (\%) it is necessary to estimate the theoretical glucose based on the initial moles of substrate (Section 0), however the aqueous fraction of bio-oil is a mixture of diverse compounds some of which may contribute to glucose formation, thus is not possible to report an accurate glucose yield value. Therefore unlike the hydrolysis of cellobiose and levoglucosan, in this section the glucose produced was reported as concentration $\left(\mathrm{g} \mathrm{L}^{-1}\right)$ instead of a percentage.

Glucose concentrations therefore will give a better idea about the amount of glucose produced, as well as the potential contribution from other components in the aqueous fraction towards glucose. Figure 11 depicts glucose and levoglucosan concentrations from the acid hydrolysis of the bio-oil aqueous fraction at different reaction times of 20 minutes (Figure 11a), 40 minutes (Figure 11b), and 60 minutes (Figure 11c).

From Figure 11 it is observed that $80{ }^{\circ} \mathrm{C}$ was not high enough to allow the conversion of potential substrates present in the aqueous fraction, even at a high catalyst to substrate ratio of 0.9 and reaction time of 60 minutes (Figure 11c). As the temperature was increased up to $100{ }^{\circ} \mathrm{C}$, slightly improvement towards substrate conversion and glucose concentration were observed. For example, at 60 minutes (Figure 11c) the concentration of glucose was positively influenced as it increased from $9 \mathrm{~g} \mathrm{~L}^{-1}$ up to $17 \mathrm{~g} \mathrm{~L}^{-1}$ as the catalyst/substrate ratio increased from 0.2 up to 0.9 .

From Figure 11, the positive effect of further increasing the hydrolysis temperature from 100 ${ }^{\circ} \mathrm{C}$ up to $120^{\circ} \mathrm{C}$ and $135{ }^{\circ} \mathrm{C}$, is clearly observed in both glucose concentrations and substrate conversion. Average glucose concentrations around $35.5 \mathrm{~g} \mathrm{~L}^{-1}$ were attained at a catalyst/substrate ratio of 0.2 and hydrolysis temperature of $135{ }^{\circ} \mathrm{C}$. At catalyst/substrate 
ratios of 0.6 and 0.9 , glucose concentrations of about $32 \mathrm{~g} \mathrm{~L}^{-1}$ were attained for different reaction times at both $120{ }^{\circ} \mathrm{C}$ and $135^{\circ} \mathrm{C}$, whereas levoglucosan was nearly depleted after just 20 minutes of reaction time. Yu and Zhang, 2003 [14], hydrolysed a pyrolysate from dry waste cotton. They found that after 20 minutes at $120^{\circ} \mathrm{C}$, and using $0.3 \mathrm{M} \mathrm{H}_{2} \mathrm{SO}_{4}$ per litre of pyrolysate, over $100 \%$ of the levoglucosan in the pyrolysate was converted into glucose. The excess of glucose produced was therefore attributed to the contribution of other compounds such as cellobiosan in the pyrolysate. For our pyrolysate we observed that at 20 minutes (Figure 11a), the glucose concentrations and substrate conversions could be further improved by increasing the hydrolysis temperature from $120^{\circ} \mathrm{C}$ up to $135^{\circ} \mathrm{C}$, particularly at a low catalyst/substrate ratio of 0.2 .

When increasing the catalyst/substrate ratio from 0.6 up to 0.9 and at $135{ }^{\circ} \mathrm{C}$, resulted in glucose concentration reductions at reaction times longer than 20 minutes. For example at 40 minutes (Figure 11b), glucose concentration was reduced from $32.5 \mathrm{~g} \mathrm{~L}^{-1}$ down to $28.56 \mathrm{~g}$ $\mathrm{L}^{-1}$; similarly at 60 minutes (Figure 11c), the concentration of glucose was reduced from $30 \mathrm{~g}$ $\mathrm{L}^{-1}$ down to $27.58 \mathrm{~g} \mathrm{~L}^{-1}$. This might indicate that at this particular temperature of $135{ }^{\circ} \mathrm{C}$ and catalyst/substrate ratio of 0.9 , glucose might not be stable and dehydrate into levoglucosan or 5- HMF, as depicted in Figure 5.

Additional hydrolysis experiments were carried out at $135^{\circ} \mathrm{C}$, at a shorter reaction time of 10 minutes, and catalyst/substrate ratios of $0.2,0.6$, and 0.9 . These results were compared with those obtained at 20 minutes and at $135^{\circ} \mathrm{C}$, in order to study the conversion of levoglucosan and glucose concentrations (Figure 12). It was found that after 10 minutes and a catalyst to substrate ratio of 0.2 , a glucose concentration of about $33.0 \mathrm{~g} \mathrm{~L}^{-1}$ could be attained, whereas the levoglucosan concentration was reduced from $31.0 \mathrm{~g} \mathrm{~L}^{-1}$ down to $3.0 \mathrm{~g} \mathrm{~L}^{-1}$. When the reaction time was increased to 20 minutes, the final glucose concentration reached $35 \mathrm{~g} \mathrm{~L}^{-1}$, whereas levoglucosan concentration was about $2.5 \mathrm{~g} \mathrm{~L}^{-1}$. This might be due to more compounds contained in the bio-oil aqueous phase continue converting after 10 minutes into glucose as the hydrolysis progresses, thus contributing to this slight increase. From Figure 12 , at 10 minutes of reaction time the increase in the catalyst/substrate from 0.6 to 0.9 , reduced the glucose concentration from $32 \mathrm{~g} \mathrm{~L}^{-1}$ down to $26 \mathrm{~g} \mathrm{~L}^{-1}$; whereas at 20 minutes the concentration of glucose was maintained around $31 \mathrm{~g} \mathrm{~L}^{-1}$ as the catalyst to substrate ratio increased from 0.6 to 0.9 .

Figure 13 shows a 3D surface map and contour plot created using the experimental data obtained from the hydrolysis of the aqueous fraction of bio-oil. In Figure 13 glucose concentration is shown as function of both temperature and catalyst/substrate ratios for the hydrolysis conditions studied. At catalyst/substrate ratios between 0.2-0.6, and temperatures 
between $120-135{ }^{\circ} \mathrm{C}$, resulted in glucose concentrations higher than $30.0 \mathrm{~g} \mathrm{~L}^{-1}$. Choi et al., [28], reported that during the hydrolysis of starch higher glucose yields were achieved at low acid concentrations around $2 \%$ and $132{ }^{\circ} \mathrm{C}$; at this temperature the acid concentration is critical as the decomposition rate of glucose is increased. A similar trend is observed in Figure $13 \mathrm{~b}$, as it seems the red area representing glucose concentrations $>35 \mathrm{~g} \mathrm{~L}^{-1}$, becomes more reduced as the temperature increases beyond $125{ }^{\circ} \mathrm{C}$, but also it concentrates in lower catalyst/substrate ratios between 0.24 and 0.43 . Glucose concentrations were reduced at catalyst/substrate ratios higher than 0.43 and at temperatures beyond $125{ }^{\circ} \mathrm{C}$. This might be due to some of the glucose product is further dehydrating into other products, when hydrolysing this particular bio-oil aqueous fraction.

Overall it was observed that during the hydrolysis of the aqueous fraction at $120{ }^{\circ} \mathrm{C}$, lower catalyst/substrate ratios required longer reactions times in order to achieve glucose concentrations similar to those attained at higher ratios and shorter reaction times. For example to attain $32.5 \mathrm{~g} \mathrm{~L}^{-1}$ of glucose at $120^{\circ} \mathrm{C}$, catalyst/substrate ratios of 0.2 and 0.6 can be used, but the reaction times required are $60 \mathrm{~min}$ and $20 \mathrm{~min}$ respectively. At $120{ }^{\circ} \mathrm{C}$, catalyst/substrate ratio of 0.9 , and different reaction times $(20,40,60 \mathrm{~min})$, the glucose concentration in the hydrolysate was maintained constant $\sim 31 \mathrm{~g} \mathrm{~L}^{-1}$. However the levoglucosan concentration increased in the product from $2 \mathrm{~g} \mathrm{~L}^{-1}$ up to $5.8 \mathrm{~g} \mathrm{~L}^{-1}$ as the reaction time was increased from $20 \mathrm{~min}$ up to $40 \mathrm{~min}$, which might indicate that the potential glucose produced at longer reaction times, dehydrated into levoglucosan due to the higher amount of acid. A similar undesirable effect was observed at higher temperature of $135^{\circ} \mathrm{C}$ and when using a catalyst/substrate ratio of 0.9 . For instance $33.4 \mathrm{~g} \mathrm{~L}^{-1}$ of glucose was attained in the hydrolysate at $10 \mathrm{~min}, 135^{\circ} \mathrm{C}$ and with a catalyst/substrate of 0.2 ; whereas the increase in the catalyst/substrate ratio to 0.6 and up to 0.9 under the same conditions, resulted in reductions in the glucose concentration down to $32 \mathrm{~g} \mathrm{~L}^{-1}$ and $26 \mathrm{~g} \mathrm{~L}^{-1}$ respectively.

Finally from Figure 13, the optimum range to attain glucose yields above $30 \mathrm{~g} \mathrm{~L}^{-1}$ were at catalyst/substrate ratios between $0.16-0.90$, and temperatures between $118-135{ }^{\circ} \mathrm{C}$. Ultimately, we report that following the acid hydrolysis of an aqueous fraction from bio-oil, the glucose produced comes not only from levoglucosan but also from other potential substrates present in this particular fraction [14, 24]. It will be therefore interesting to create a similar mixture using other glucose contributors and undertake hydrolysis experiments in order to identify and verify this particular trend. 


\section{Conclusions}

This research demonstrates the feasibility of producing glucose from the acid hydrolysis of anhydrosugar model compounds as well as anhydrosugars contained in the aqueous fraction of bio-oil from the fast pyrolysis of birch-wood.

Acid hydrolysis of cellobiose and levoglucosan can achieve substrate conversions close to $100 \%$ and glucose yields as high as $96 \%$ within various ranges of hydrolysis conditions including temperature, reaction time and catalyst to substrate ratio.

The aqueous fraction from bio-oil, containing mainly levoglucosan can be hydrolysed at $135{ }^{\circ} \mathrm{C}, 20$ mins reaction time and with a levoglucosan to $\mathrm{H}_{2} \mathrm{SO}_{4}$ molar ratio of 0.2 , for the production of $35.3 \mathrm{~g} \mathrm{~L}^{-1}$ of glucose (117\% yield). At these conditions a conversion of levoglucosan was $92 \%$.

Hydrolysing the bio-oil aqueous fraction at $135^{\circ} \mathrm{C}$, with a reaction time as short as 10 $\mathrm{min}$, and catalyst/substrate ratios of 0.2 , can result in conversions of levoglucosan of $90 \%$ and a glucose concentrations of $32.4 \mathrm{~g} \mathrm{~L}^{-1}$. This short residence time can promote a more continuous operation when scaling up acid hydrolysis.

For the hydrolysis of the aqueous fraction at $120^{\circ} \mathrm{C}$, the highest glucose concentration of $32.5 \mathrm{~g} \mathrm{~L}^{-1}$ can be achieved at $20 \mathrm{~min}$, and a catalyst/substrate of 0.6 , or at 60 minutes and a catalyst/substrate of 0.2 .

The results reported for the hydrolysis of this particular bio-oil fraction, can serve as a basis for selecting acid hydrolysis conditions for a larger scale operation. With that being said, further work is required on the effect and presence of inhibitors in the bio-oil, particularly when fermentation is considered as a next process stage. 


\section{Acknowledgements}

This research project is kindly funded by Nova Pangaea Technologies and Aston University in the United Kingdom. The funding and technical advice from Nova Pangaea, as well as the academic support and feedback from the co-authors are gratefully acknowledged. 


\section{References}

[1] J. Piskorz, D.S. Radlein, D.S. Scott, S. Czernik, Pretreatment of Wood and Cellulose for Production of Sugars by Fast Pyrolysis, Journal of Analytical and Applied Pyrolysis, 1989, 16, 127-142, 10.1016/0165-2370(89)85012-0.

[2] A.V. Bridgwater, D. Meier, D. Radlein, An overview of fast pyrolysis of biomass, Org Geochem, 1999, 30, 1479-1493, 10.1016/S0146-6380(99)00120-5.

[3] D. Mohan, C.U. Pittman, P.H. Steele, Pyrolysis of Wood/Biomass for Bio-oil: A Critical Review, Energ Fuel, 2006, 20, 848-889, 10.1021/ef0502397.

[4] V. Choudhary, S.H. Mushrif, C. Ho, A. Anderko, V. Nikolakis, N.S. Marinkovic, A.I. Frenkel, S.I. Sandler, D.G. Vlachos, Insights into the Interplay of Lewis and Bronsted Acid Catalysts in Glucose and Fructose Conversion to 5-(Hydroxymethyl)furfural and Levulinic Acid in Aqueous Media, J Am Chem Soc, 2013, 135, 3997-4006, 10.1021/ja3122763.

[5] A.V. Bridgwater, G.V.C. Peacocke, Fast pyrolysis processes for biomass, Renew Sust Energ Rev, 2000, 4, 1-73, 10.1016/S1364-0321(99)00007-6.

[6] A. Oasmaa, S. Czernik, Fuel oil quality of biomass pyrolysis oils - State of the art for the end user, Energ Fuel, 1999, 13, 914-921, 10.1021/ef980272b.

[7] J. Lian, S. Chen, S. Zhou, Z. Wang, J. O'Fallon, C.-Z. Li, M. Garcia-Perez, Separation, hydrolysis and fermentation of pyrolytic sugars to produce ethanol and lipids, Bioresource technology, 2010, 101, 9688-9699, 10.1016/j.biortech.2010.07.071.

[8] M. Garcia-Perez, X.S. Wang, J. Shen, M.J. Rhodes, F.J. Tian, W.J. Lee, H.W. Wu, C.Z. $\mathrm{Li}$, Fast pyrolysis of oil mallee woody biomass: Effect of temperature on the yield and quality of pyrolysis products, Industrial \& Engineering Chemistry Research, 2008, 47, 1846-1854, 10.1021/ie071497p.

[9] N.M. Bennett, S.S. Helle, S.J. Duff, Extraction and hydrolysis of levoglucosan from pyrolysis oil, Bioresource technology, 2009, 100, 6059-6063, 10.1016/j.biortech.2009.06.067.

[10] G.W. Lyu, S.; Zhang, H., Estimation and comparison of bio-oil components from different pyrolysis conditions, Frontiers in Energy Research, 2015, 3, 10.3389/fenrg.2015.00028.

[11] K. Sipila, E. Kuoppala, L. Fagernas, A. Oasmaa, Characterization of biomass-based flash pyrolysis oils, Biomass Bioenerg, 1998, 14, 103-113, 10.1016/S0961-9534(97)10024-1. [12] Q. Li, P.H. Steele, B. Mitchell, L.L. Ingram, F. Yu, The Addition of Water to Extract Maximum Levoglucosan from the Bio-oil Produced via Fast Pyrolysis of Pretreated Loblolly Pinewood, Bioresources, 2013, 8, 1868-1880.

[13] L. Li, H.X. Zhang, Preparing levoglucosan derived from waste material by pyrolysis, Energ Source, 2004, 26, 1053-1059, 10.1080/00908310490494559.

[14] Z. Yu, H. Zhang, Ethanol fermentation of acid-hydrolyzed cellulosic pyrolysate with Saccharomyces cerevisiae, Bioresource technology, 2003, 90, 95-100, 10.1016/S09608524(03)00093-2.

[15] K. Meile, A. Zhurinsh, B. Spince, G. Dobele, Application of Ion Exchange Resins in the Separation of Valuable Compounds from Wood Pyrolysis Liquids, Key Eng Mater, 2014, 604, 232-235, 10.4028/www.scientific.net/KEM.604.232.

[16] S. Czernik, A.V. Bridgwater, Overview of applications of biomass fast pyrolysis oil, Energ Fuel, 2004, 18, 590-598, 10.1021/ef034067u.

[17] D.S. Scott, J. Piskorz, D. Radlein, P. Majerski, Process for the production of anhydrosugars from lignin and cellulose containing biomass by pyrolysis, USA, 1995.

[18] G. Dobele, T. Dizhbite, G. Rossinskaja, G. Telysheva, D. Mier, S. Radtke, O. Faix, Pretreatment of biomass with phosphoric acid prior to fast pyrolysis - A promising method for obtaining 1,6-anhydrosaccharides in high yields, Journal of Analytical and Applied Pyrolysis, 2003, 68-9, 197-211, 10.1016/S0165-2370(03)00063-9.

[19] D. Mourant, Z.H. Wang, M. He, X.S. Wang, M. Garcia-Perez, K.C. Ling, C.Z. Li, Mallee wood fast pyrolysis: Effects of alkali and alkaline earth metallic species on the yield and composition of bio-oil, Fuel, 2011, 90, 2915-2922, 10.1016/j.fuel.2011.04.033. 
[20] P.R. Patwardhan, J.A. Satrio, R.C. Brown, B.H. Shanks, Influence of inorganic salts on the primary pyrolysis products of cellulose, Bioresource technology, 2010, 101, 4646-4655, 10.1016/j.biortech.2010.01.112.

[21] D.S. Scott, L. Paterson, J. Piskorz, D. Radlein, Pretreatment of poplar wood for fast pyrolysis: rate of cation removal, Journal of Analytical and Applied Pyrolysis, 2001, 57, 169176, 10.1016/S0165-2370(00)00108-X.

[22] J.N. Lian, S.L. Chen, S.A. Zhou, Z.H. Wang, J. O'Fallon, C.Z. Li, M. Garcia-Perez, Separation, hydrolysis and fermentation of pyrolytic sugars to produce ethanol and lipids, Bioresource technology, 2010, 101, 9688-9699, 10.1016/j.biortech.2010.07.071.

[23] C. Schwarzinger, I. Tanczos, H. Schmidt, Levoglucosan, cellobiose and their acetates as model compounds for the thermally assisted hydrolysis and methylation of cellulose and cellulose acetate, Journal of Analytical and Applied Pyrolysis, 2002, 62, 179-196, 10.1016/S0165-2370(01)00114-0.

[24] S. Helle, N.M. Bennett, K. Lau, J.H. Matsui, S.J. Duff, A kinetic model for production of glucose by hydrolysis of levoglucosan and cellobiosan from pyrolysis oil, Carbohydrate research, 2007, 342, 2365-2370, 10.1016/j.carres.2007.07.016.

[25] P. Bhaumik, P.L. Dhepe, Conversion of Biomass into Sugars, in: D. Murzin, O. Simakova (Eds.) Biomass Sugars for Non-Fuel Applications, RSC Green Chemistry, United Kingdom, 2015.

[26] Q.A. Nguyen, M.P. Tucker, F.A. Keller, F.P. Eddy, Two-stage dilute-acid pretreatment of softwoods, Applied Biochemistry and Biotechnology, 2000, 84, 561-576, 10.1385/abab:8486:1-9:561.

[27] G. Ucar, Pretreatment of poplar by acid and alkali for enzymatic hydrolysis, Wood Science and Technology, 1990, 24, 171-180, 10.1007/bf00229052.

[28] C.H. Choi, A.P. Mathews, Two-step acid hydrolysis process kinetics in the saccharification of low-grade biomass .1. Experimental studies on the formation and degradation of sugars, Bioresource technology, 1996, 58, 101-106, 10.1016/S09608524(96)00089-2.

[29] A. Esteghlalian, A.G. Hashimoto, J.J. Fenske, M.H. Penner, Modeling and optimization of the dilute-sulfuric-acid pretreatment of corn stover, poplar and switchgrass, Bioresource technology, 1997, 59, 129-136, 10.1016/S0960-8524(97)81606-9.

[30] S.I. Mussatto, Biomass Fractionation Technologies for a Lignocellulosic Feedstock Based Biorefinery, Elsevier, Oxford, UK, 2016, pp. 674.

[31] W. Deng, R. Lobo, W. Setthapun, S.T. Christensen, J.W. Elam, C.L. Marshall, Oxidative Hydrolysis of Cellobiose to Glucose, Catal Lett, 2011, 141, 498-506, 10.1007/s10562-0100532-8.

[32] Y. Yu, Y.W. Chua, H.W. Wu, Characterization of Pyrolytic Sugars in Bio-Oil Produced from Biomass Fast Pyrolysis, Energ Fuel, 2016, 30, 4145-4149, 10.1021/acs.energyfuels.6b00464.

[33] C. Tessini, M. Vega, N. Muller, L. Bustamante, D. von Baer, A. Berg, C. Mardones, High performance thin layer chromatography determination of cellobiosan and levoglucosan in bio-oil obtained by fast pyrolysis of sawdust, Journal of Chromatography A, 2011, 1218, 3811-3815, 10.1016/j.chroma.2011.04.037.

[34] X. Zhang, W. Yang, C. Dong, Levoglucosan formation mechanisms during cellulose pyrolysis, Journal of Analytical and Applied Pyrolysis, 2013, 104, 19-27, 10.1016/j.jaap.2013.09.015.

[35] N.S. Mosier, C.M. Ladisch, M.R. Ladisch, Characterization of acid catalytic domains for cellulose hydrolysis and glucose degradation, Biotechnology and Bioengineering, 2002, 79, 610-618, 10.1002/bit.10316.

[36] X. Peng, X.-G. Meng, C. Mi, X.-H. Liao, Hydrolysis of cellobiose to monosaccharide catalyzed by functional Lanthanum(iii) metallomicelle, RSC Adv., 2015, 5, 9348-9353, 10.1039/c4ra14521f.

[37] M. Ohara, A. Takagaki, S. Nishimura, K. Ebitani, Syntheses of 5-hydroxymethylfurfural and levoglucosan by selective dehydration of glucose using solid acid and base catalysts, Appl Catal a-Gen, 2010, 383, 149-155, 10.1016/j.apcata.2010.05.040. 
[38] H. Satoh, K. Takahashi, H. Kaga, Production of Levoglucosan from Glucose in High Temperature Water, Asian Pacific Confederation of Chemical Engineering congress program and abstracts, 2004, 2004, 823-823, 10.11491/apcche.2004.0.823.0.

[39] B. Girisuta, L.P.B.M. Janssen, H.J. Heeres, Kinetic study on the acid-catalyzed hydrolysis of cellulose to levulinic acid, Industrial \& Engineering Chemistry Research, 2007, 46, 1696-1708, 10.1021/ie061186z.

[40] C. Antonetti, D. Licursi, S. Fulignati, G. Valentini, A.M.R. Galletti, New Frontiers in the Catalytic Synthesis of Levulinic Acid: From Sugars to Raw and Waste Biomass as Starting Feedstock, Catalysts, 2016, 6, 10.3390/catal6120196.

[41] A.S. Amarasekara, L.D. Williams, C.C. Ebede, Mechanism of the dehydration of Dfructose to 5-hydroxymethylfurfural in dimethyl sulfoxide at 150 degrees C: an NMR study, Carbohydrate research, 2008, 343, 3021-3024, 10.1016/j.carres.2008.09.008.

[42] J. Guan, Q.A. Cao, X.C. Guo, X.D. Mu, The mechanism of glucose conversion to 5hydroxymethylfurfural catalyzed by metal chlorides in ionic liquid: A theoretical study, Comput Theor Chem, 2011, 963, 453-462, 10.1016/j.comptc.2010.11.012.

[43] G. Tsilomelekis, M.J. Orella, Z.X. Lin, Z.W. Cheng, W.Q. Zheng, V. Nikolakis, D.G. Vlachos, Molecular structure, morphology and growth mechanisms and rates of 5hydroxymethyl furfural (HMF) derived humins, Green Chemistry, 2016, 18, 1983-1993, 10.1039/c5gc01938a.

[44] I. van Zandvoort, Y. Wang, C.B. Rasrendra, E.R.H. van Eck, P.C.A. Bruijnincx, H.J. Heeres, B.M. Weckhuysen, Formation, Molecular Structure, and Morphology of Humins in Biomass Conversion: Influence of Feedstock and Processing Conditions, ChemSusChem, 2013, 6, 1745-1758, 10.1002/cssc.201300332.

[45] B. Girisuta, Levulinic acid from lignocellulosic biomass, Faculty of Mathematics and Natural Sciences, University of Groningen, Groningen, 2007, pp. 148.

[46] B.F.M. Kuster, 5-Hydroxymethylfurfural (HMF). A Review Focussing on its Manufacture, Starch - Stärke, 1990, 42, 314-321, 10.1002/star.19900420808.

[47] C. Moreau, R. Durand, S. Razigade, J. Duhamet, P. Faugeras, P. Rivalier, P. Ros, G. Avignon, Dehydration of fructose to 5-hydroxymethylfurfural over $\mathrm{H}$-mordenites, Applied Catalysis A: General, 1996, 145, 211-224, 10.1016/0926-860X(96)00136-6.

[48] P.R. Patwardhan, Understanding the product distribution from biomass fast pyrolysis, Chemical Engineering, lowa State University, Ames, lowa, USA, 2010, pp. 162.

[49] K. Meile, Zhurinsh, A., Dobele, G., Characterization of the anhydrosugar content in pyrolysis liquids with column chromatography and iodometric titration, Energetika, 2014, 60, 162-168.

[50] Q. Li, P.H. Steele, F. Yu, B. Mitchell, E.M. Hassan, Pyrolytic spray increases levoglucosan production during fast pyrolysis, Journal of Analytical and Applied Pyrolysis, 2013, 100, 33-40, 10.1016/j.jaap.2012.11.013.

[51] S.R.G. Oudenhoven, R.J.M. Westerhof, S.R.A. Kersten, Fast pyrolysis of organic acid leached wood, straw, hay and bagasse: Improved oil and sugar yields, Journal of Analytical and Applied Pyrolysis, 2015, 116, 253-262, 10.1016/j.jaap.2015.09.003. 


\section{List of Tables}

Table 1. Coded factors matrix for the required experiments

10

11

12

13

14

15

16

17

18

19

20

21

22

23

24

25

26

27

28

29

30

31

32

33

34

35

36

37

38

39

40

41

42

43

44

45

46

47

48

49

50

51

52

53

54

55

56

57

58

59

60

ACS Paragon Plus Environment 
Table 1. Coded factors matrix for the required experiments

\begin{tabular}{|c|c|c|c|}
\hline Experiment & $\begin{array}{c}\text { Temperature } \\
\left({ }^{\circ} \mathrm{C}\right)\end{array}$ & $\begin{array}{l}\text { Reaction time } \\
\text { (min) }\end{array}$ & $\begin{array}{l}\text { Catalyst/substrate } \\
\text { molar ratio }\end{array}$ \\
\hline & $x_{1}$ & $x_{2}$ & $x_{3}$ \\
\hline 1 & -1 & -1 & -1 \\
\hline 2 & -1 & -1 & 0 \\
\hline 3 & -1 & -1 & 1 \\
\hline 4 & 0 & -1 & -1 \\
\hline 5 & 0 & -1 & 0 \\
\hline 6 & 0 & -1 & 1 \\
\hline 7 & 1 & -1 & -1 \\
\hline 8 & 1 & -1 & 0 \\
\hline 9 & 1 & -1 & 1 \\
\hline 10 & -1 & 0 & -1 \\
\hline 11 & -1 & 0 & 0 \\
\hline 12 & -1 & 0 & 1 \\
\hline 13 & 0 & 0 & -1 \\
\hline 14 & 0 & 0 & 0 \\
\hline 15 & 0 & 0 & 1 \\
\hline 16 & 1 & 0 & -1 \\
\hline 17 & 1 & 0 & 0 \\
\hline 18 & 1 & 0 & 1 \\
\hline 19 & -1 & 1 & -1 \\
\hline 20 & -1 & 1 & 0 \\
\hline 21 & -1 & 1 & 1 \\
\hline 22 & 0 & 1 & -1 \\
\hline 23 & 0 & 1 & 0 \\
\hline 24 & 0 & 1 & 1 \\
\hline 25 & 1 & 1 & -1 \\
\hline 26 & 1 & 1 & 0 \\
\hline 27 & 1 & 1 & 1 \\
\hline
\end{tabular}




\section{List of Figures}

Figure 1. Schematic diagram of the autoclave reaction system used for acid hydrolysis

Figure 2. Hydrolysis of cellobiosan into glucose (adapted from Helle et al, 2007 [24])

Figure 3. Cellobiose conversion (\%) and glucose yields (\%) at different reaction times: (a) 20 min; (b) 40 min; and (c) 60 min

Figure 4. Cellobiose conversion (\%) and Glucose selectivity (\%) at 60 minutes reaction time, different temperatures and catalyst/cellobiose ratios

Figure 5. Dehydration reactions of glucose

Figure 6. Glucose yields (\%) from the hydrolysis of cellobiose at different temperatures and catalyst to substrate ratios: (a) 3D surface area; (b) contour plot

Figure 7. Levoglucosan conversion (\%) and glucose yields (\%) at different reaction times: (a) $20 \mathrm{~min}$; (b) $40 \mathrm{~min}$; and (c) $60 \mathrm{~min}$

Figure 8. Levoglucosan conversions (\%) and glucose yields (\%) at catalyst/substrate molar ratio 0.2 , and temperatures of $\| 80^{\circ} \mathrm{C} ; \bullet 100^{\circ} \mathrm{C} ; \Delta 110^{\circ} \mathrm{C}$ (calculated); $\bullet 120^{\circ} \mathrm{C}$.

Figure 9. Glucose yields (\%) from the acid hydrolysis of levoglucosan at different temperatures and catalyst to substrate ratios: (a) 3D surface area; (b) contour plot

Figure 10. GC-MS chromatogram of the aqueous fraction of bio-oil

Figure 11. Concentrations of Glucose and levoglucosan $\left(\mathrm{g} \mathrm{L}^{-1}\right)$ at different temperatures, molar ratios and reaction times of (a) $20 \mathrm{~min}$; (b) $40 \mathrm{~min}$; (c) $60 \mathrm{~min}$

Figure 12. Concentrations of levoglucosan and glucose from the hydrolysis of pyrolysis oil at $135^{\circ} \mathrm{C}, 10$ and 20 minutes reaction time and $0.2,0.6$, and 0.9 catalyst/substrate ratios.

Figure 13. Glucose concentration from the acid hydrolysis of pyrolysis oil: (a) 3D surface area; (b) contour plot 
Figure 1. Schematic diagram of the autoclave reaction system used for acid hydrolysis

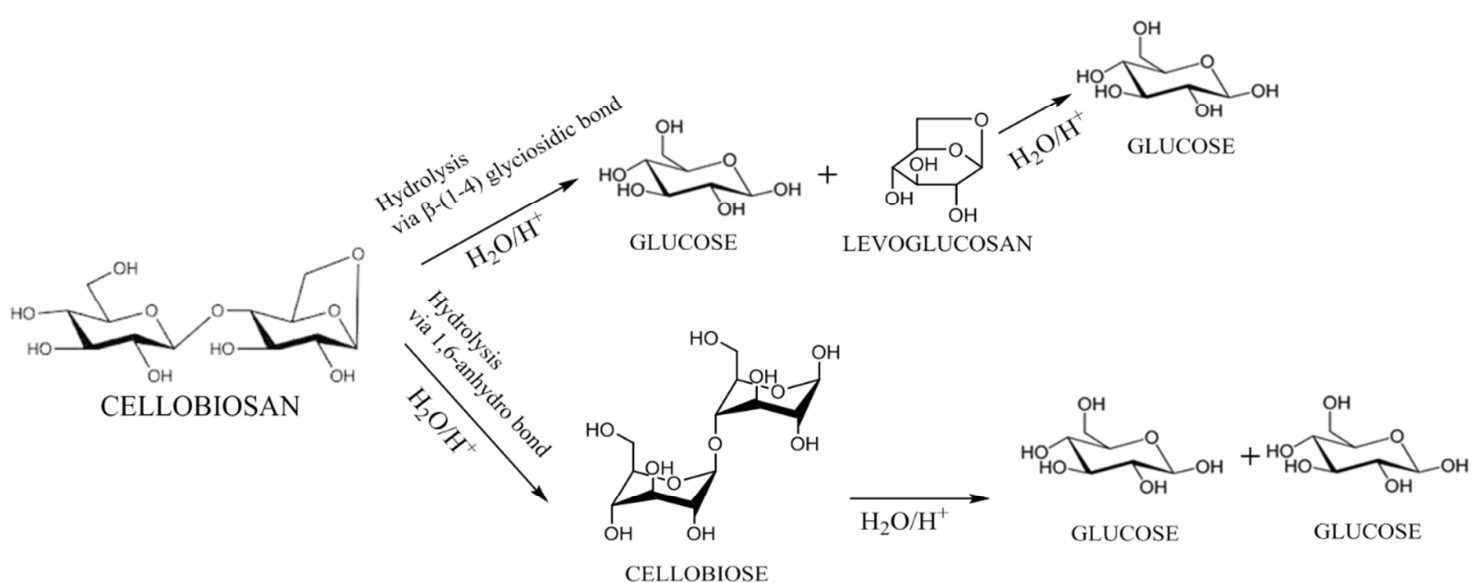

Figure 2. Hydrolysis of cellobiosan into glucose (adapted from Helle et al, 2007 [24]) 


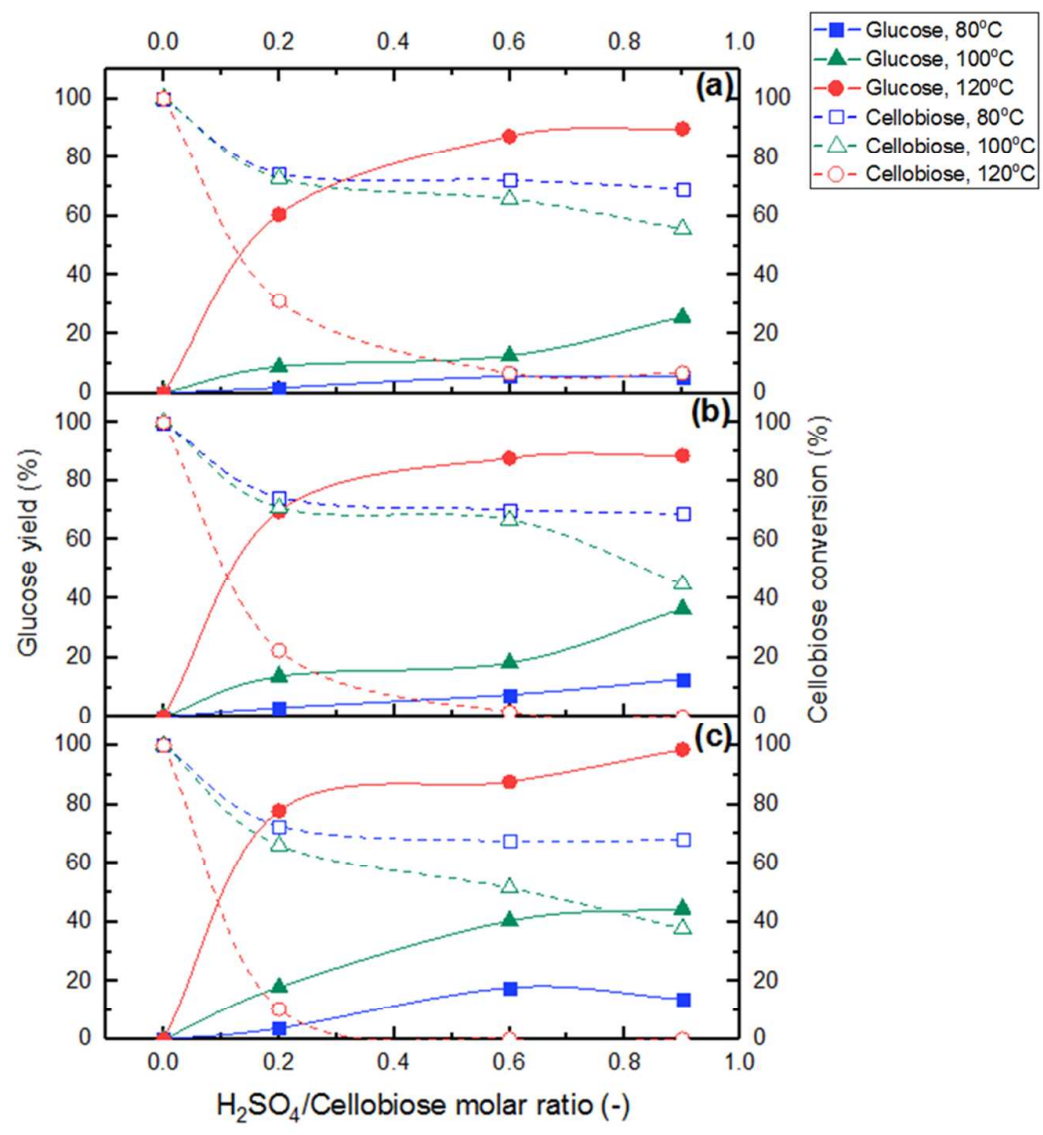

Figure 3. Cellobiose conversion (\%) and glucose yields (\%) at different reaction times: (a) 20 min; (b) $40 \mathrm{~min}$; and (c) $60 \mathrm{~min}$ 


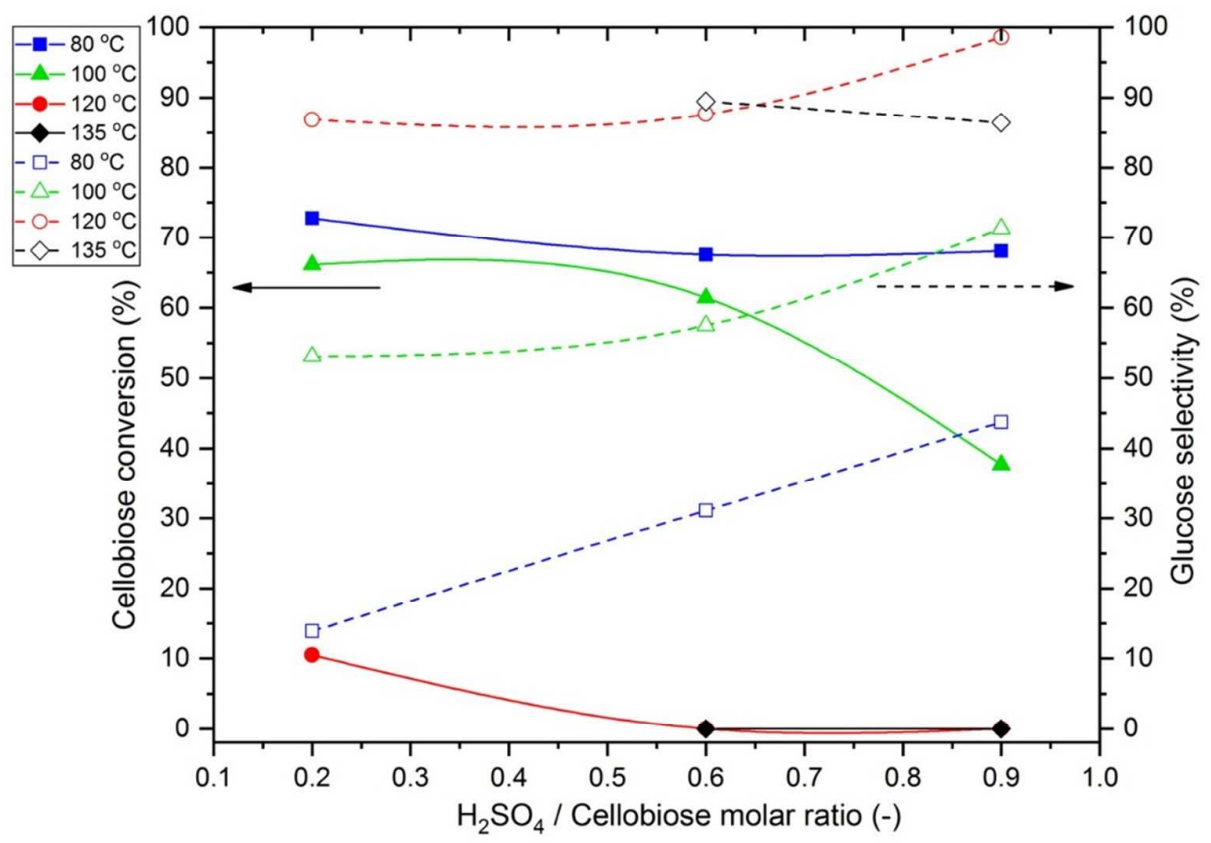

Figure 4. Cellobiose conversion (\%) and Glucose selectivity (\%) at 60 minutes reaction time, different temperatures and catalyst/cellobiose ratios

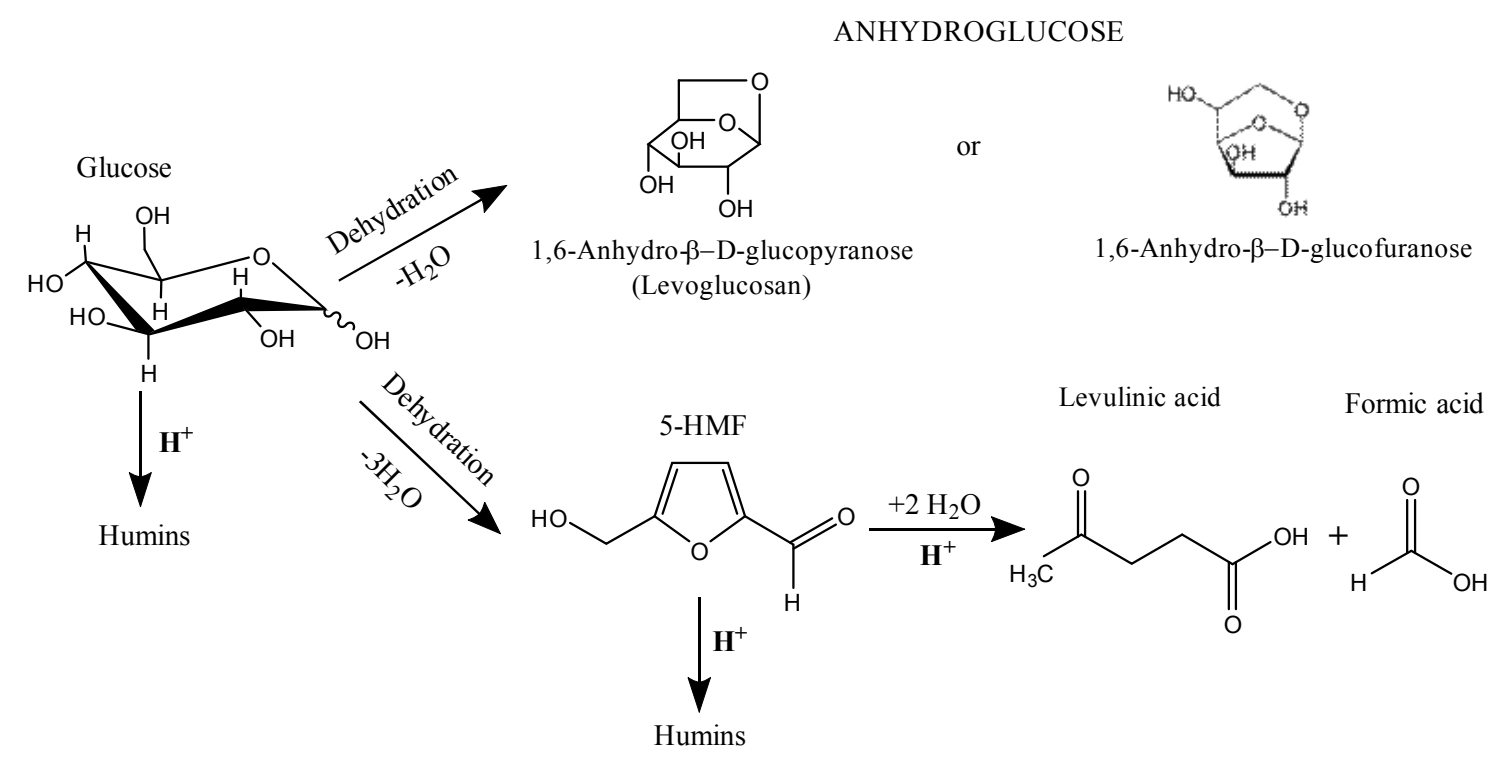

Figure 5. Dehydration reactions of glucose 

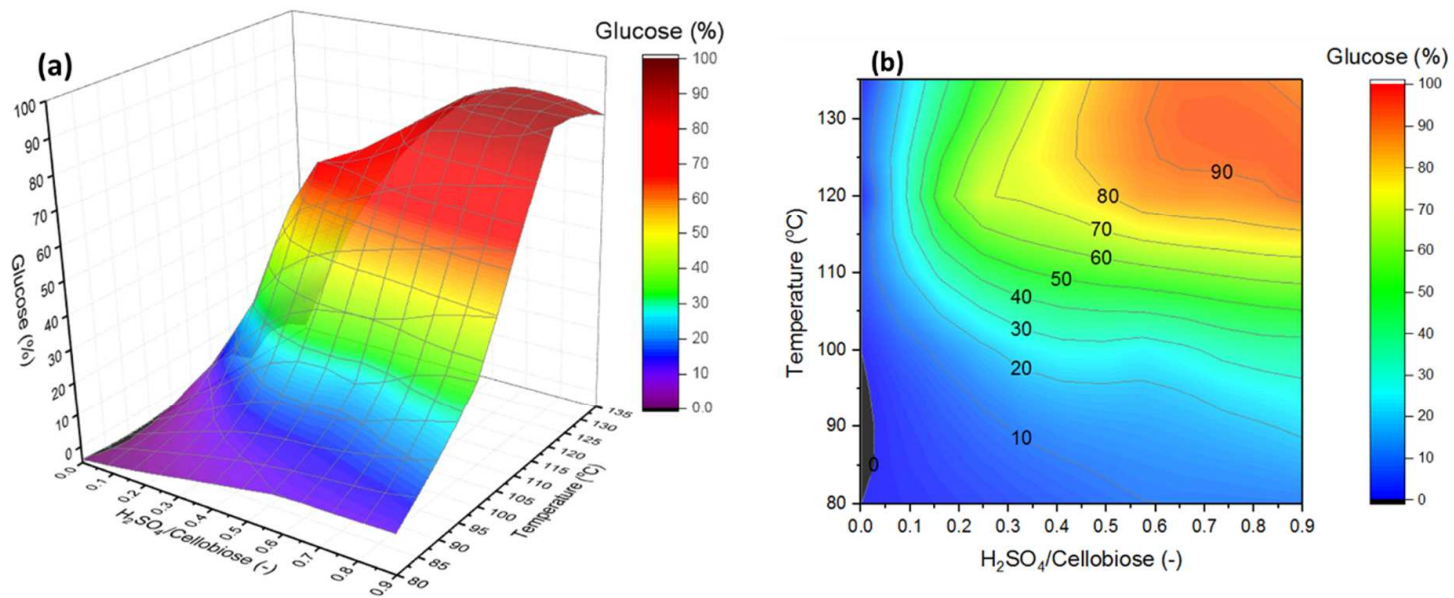

Figure 6. Glucose yields (\%) from the hydrolysis of cellobiose at different temperatures and catalyst to substrate ratios: (a) 3D surface area; (b) contour plot

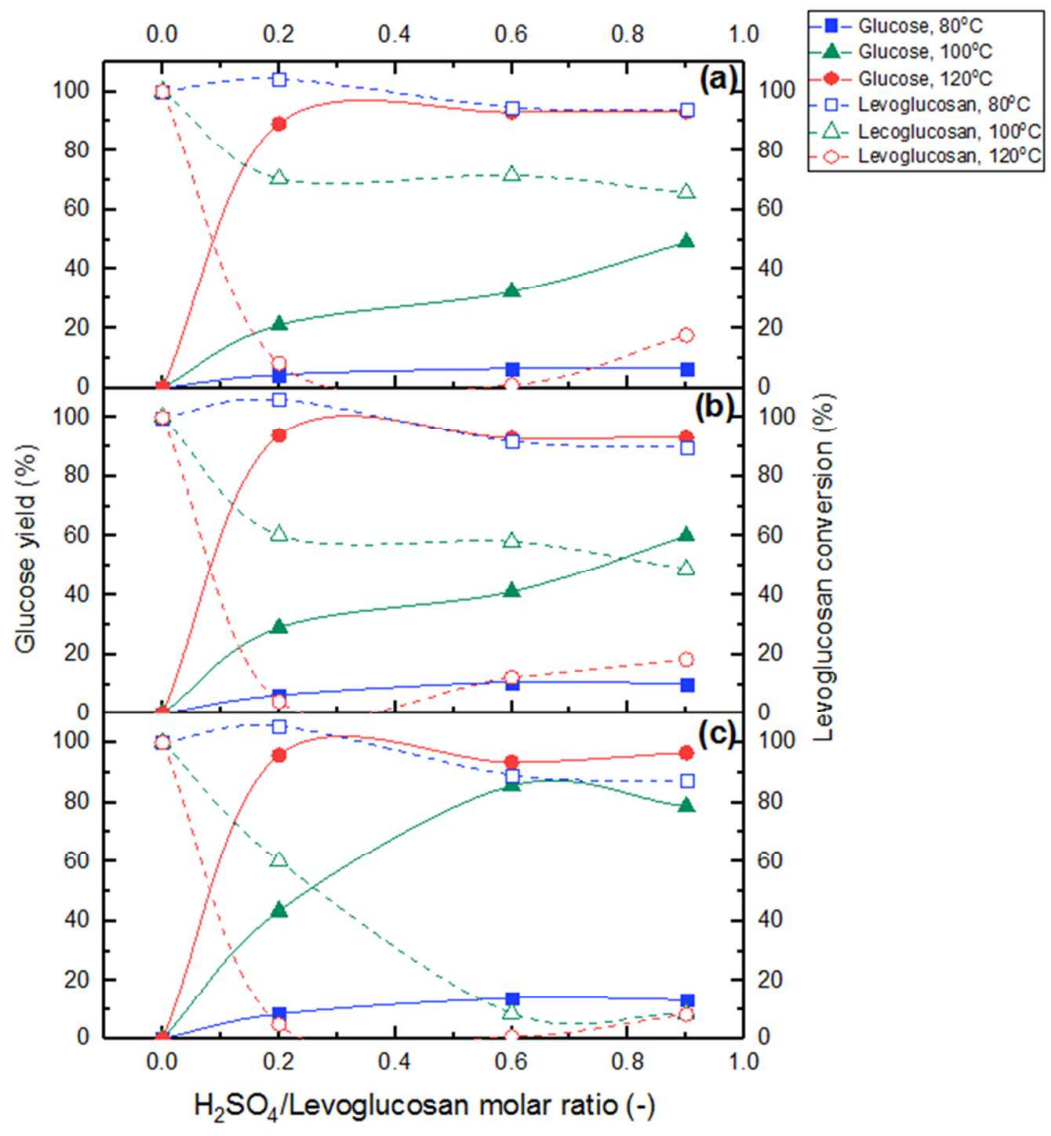

Figure 7. Levoglucosan conversion (\%) and glucose yields (\%) at different reaction times: (a) $20 \mathrm{~min}$; (b) $40 \mathrm{~min}$; and (c) $60 \mathrm{~min}$ 

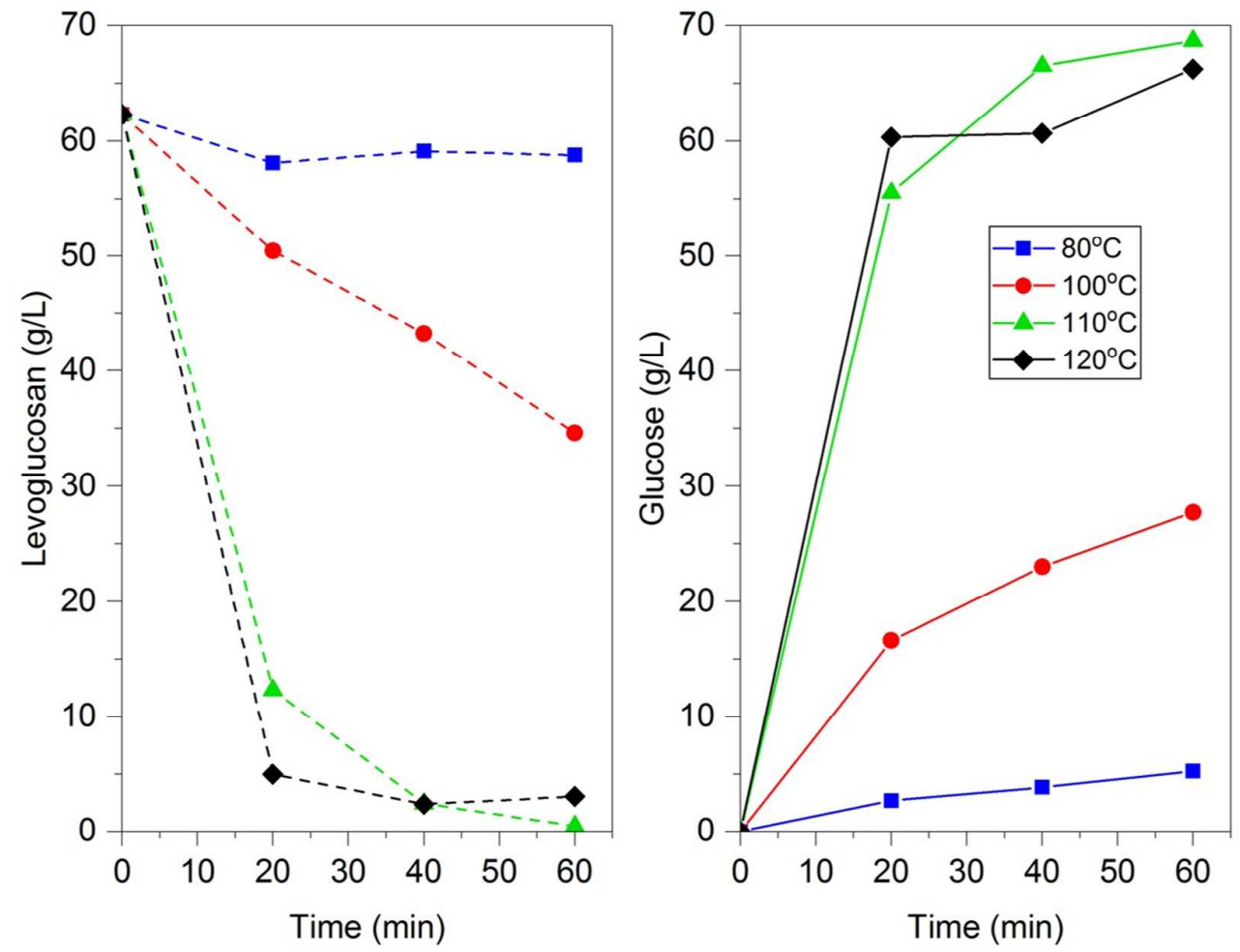

Figure 8. Levoglucosan conversions (\%) and glucose yields (\%) at catalyst/substrate molar ratio 0.2 , and temperatures of $=80^{\circ} \mathrm{C} ; \bullet 100^{\circ} \mathrm{C} ; \Delta 110^{\circ} \mathrm{C}$ (calculated); $\triangleleft 120^{\circ} \mathrm{C}$.
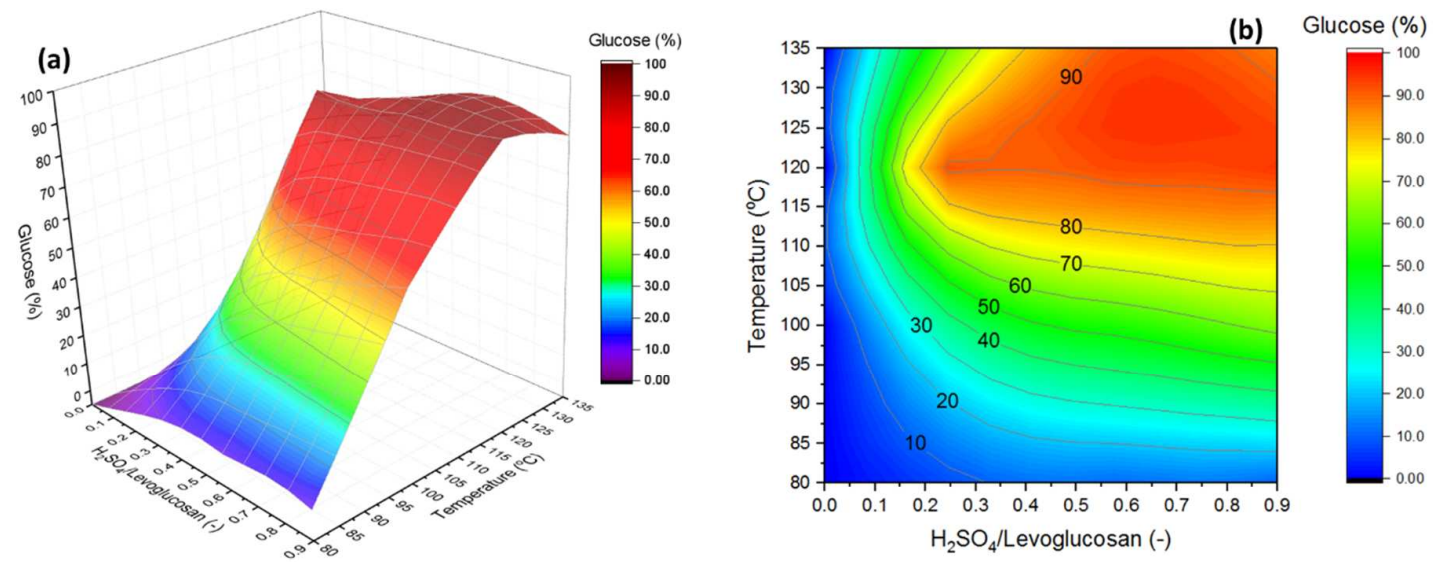

Figure 9. Glucose yields (\%) from the acid hydrolysis of levoglucosan at different temperatures and catalyst to substrate ratios: (a) 3D surface area; (b) contour plot 


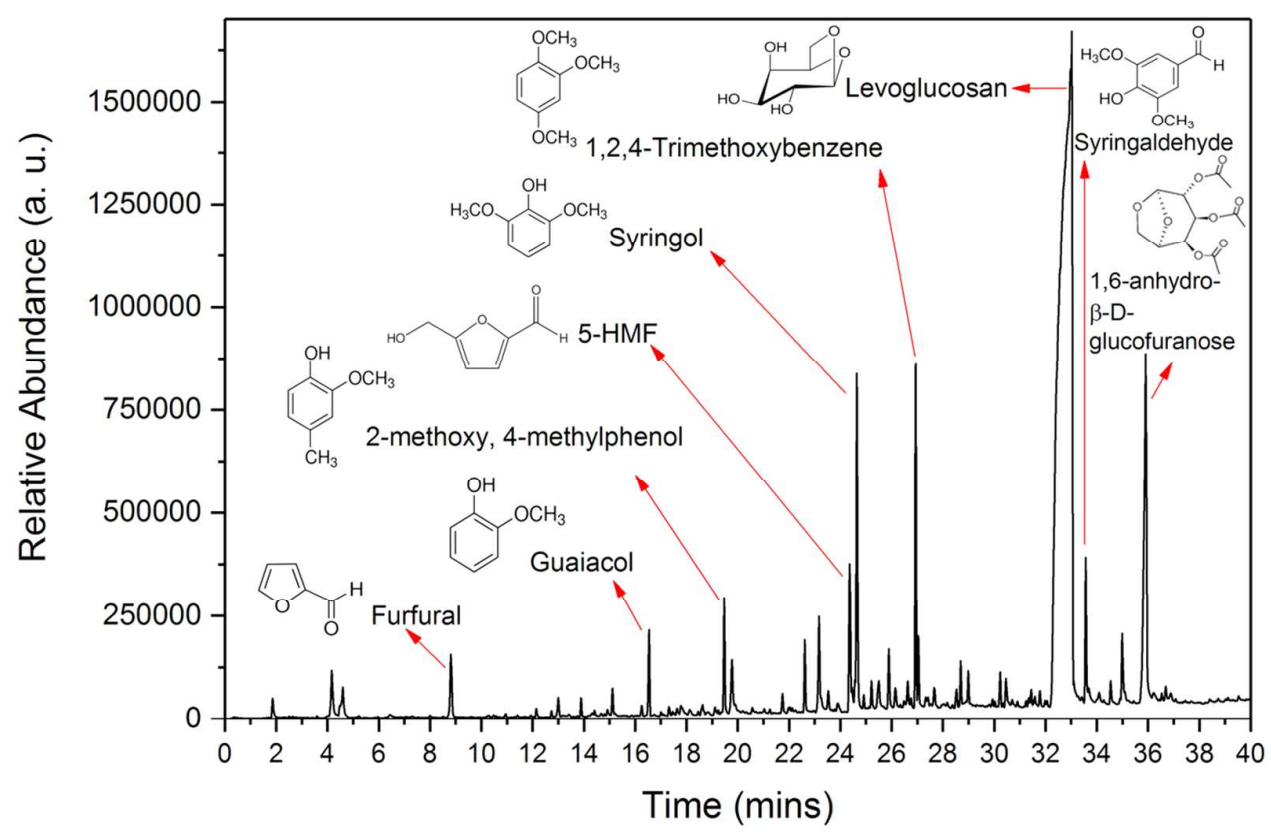

Figure 10. GC-MS chromatogram of the aqueous fraction of bio-oil
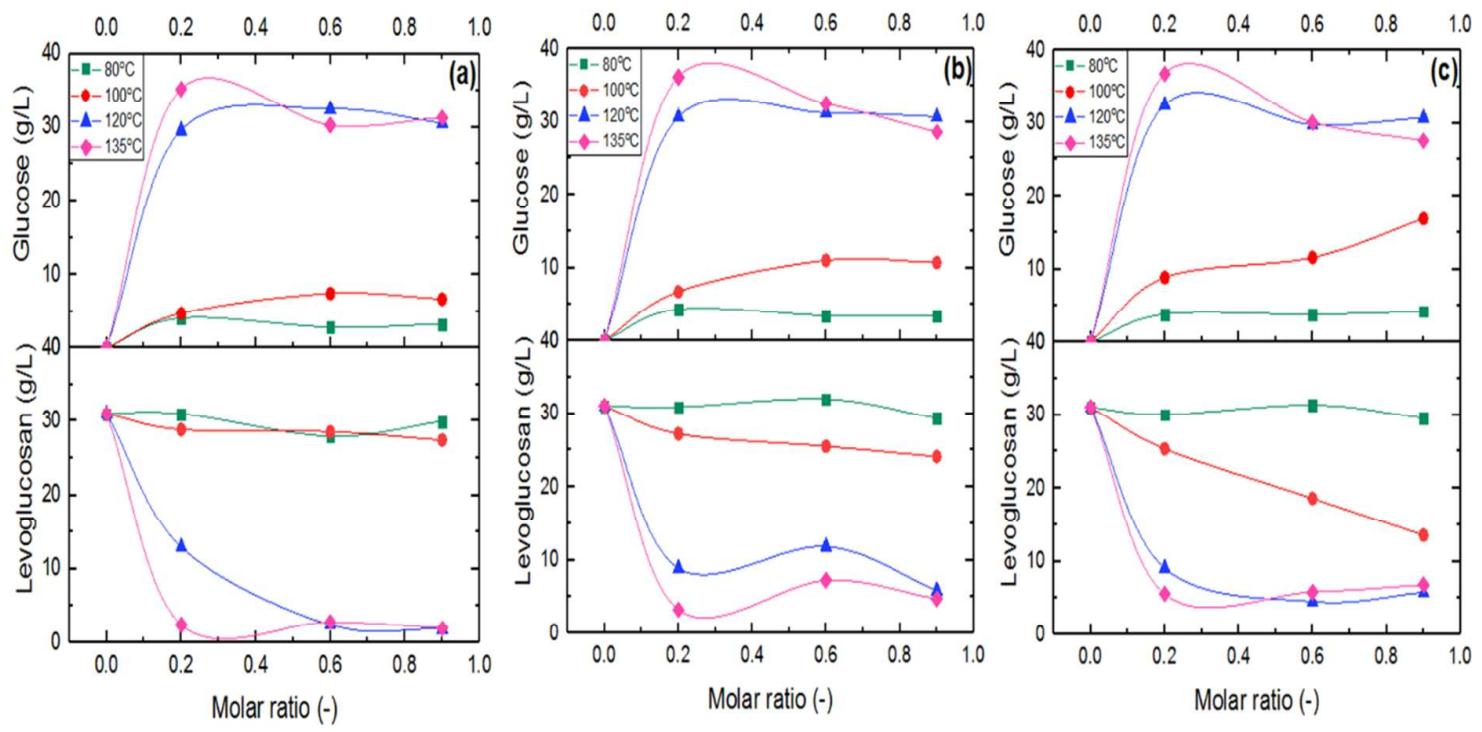

Figure 11. Concentrations of Glucose and levoglucosan $\left(\mathrm{g} \mathrm{L}^{-1}\right)$ at different temperatures, molar ratios and reaction times of (a) $20 \mathrm{~min}$; (b) $40 \mathrm{~min}$; (c) $60 \mathrm{~min}$ 
2

3

4

5

6

7

8

9

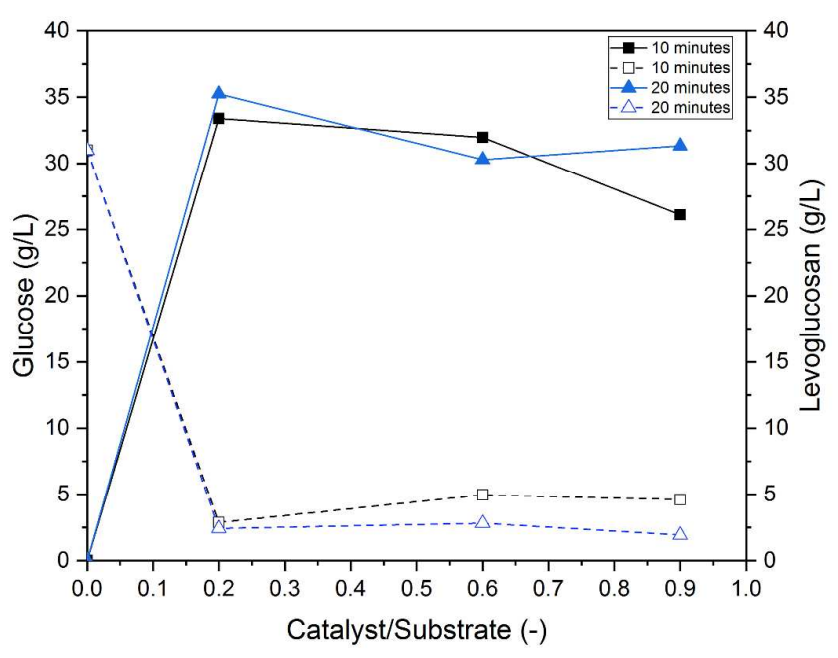

Figure 12. Concentrations of levoglucosan and glucose from the hydrolysis of pyrolysis oil at $135{ }^{\circ} \mathrm{C}, 10$ and 20 minutes reaction time and $0.2,0.6$, and 0.9 catalyst/substrate ratios.
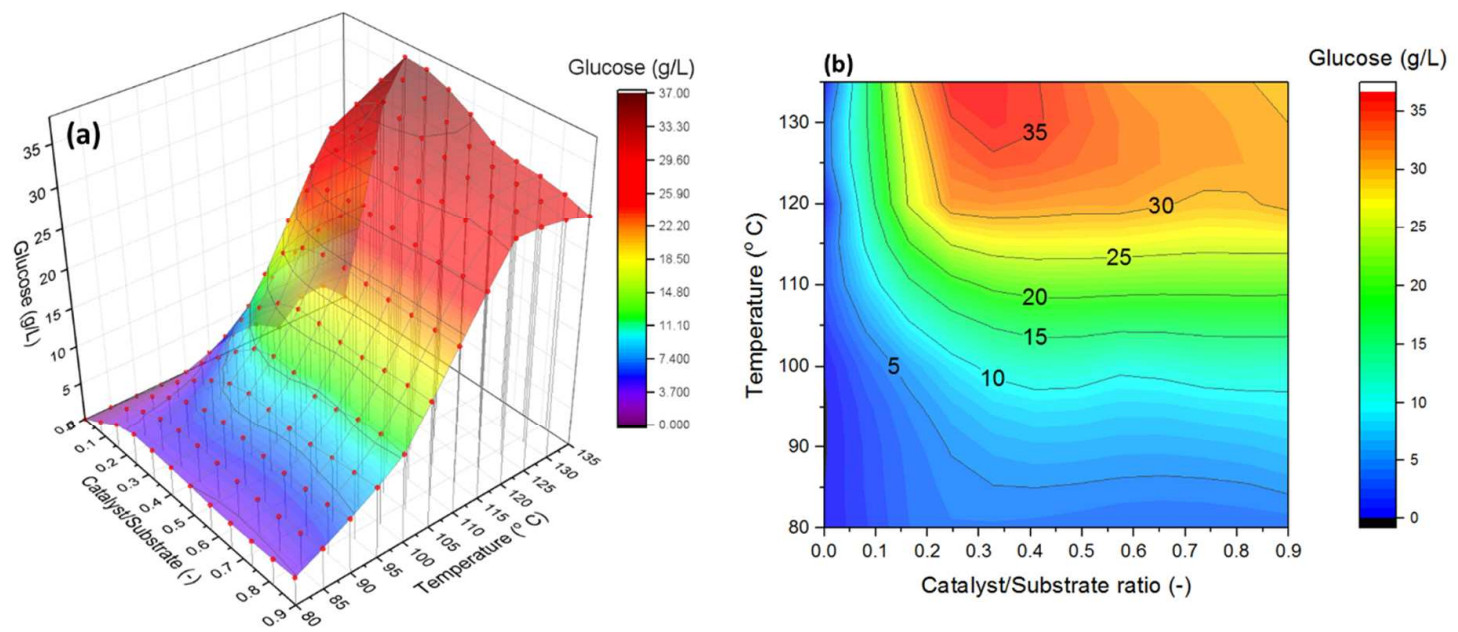

Figure 13. Glucose concentration from the acid hydrolysis of pyrolysis oil: (a) 3D surface area; (b) contour plot 


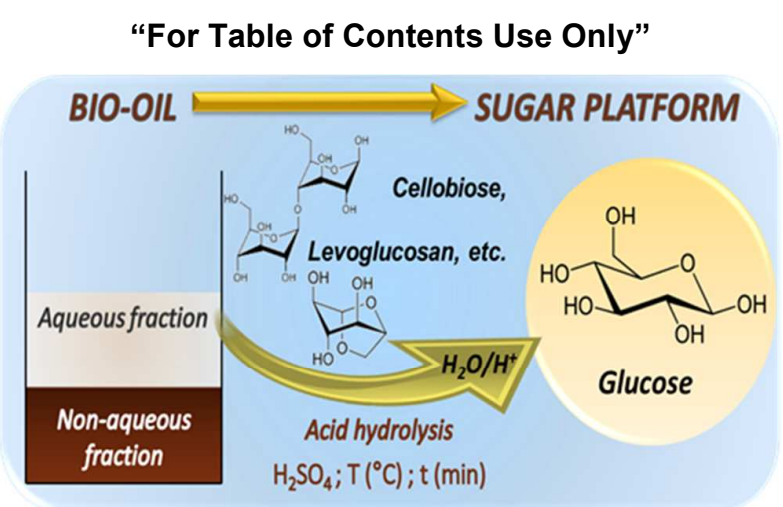

Synopsis

This paper envisages a conversion pathway from a biomass renewable feedstock into glucose which is a high-value sugar platform. 